\title{
Estimating Private Equity Returns from Limited Partner Cash Flows
}

\author{
Andrew Ang, Bingxu Chen, William N. Goetzmann, and Ludovic Phalippou*
}

June 18, 2017

\begin{abstract}
We introduce a methodology to estimate the historical time-series of returns to investment in private equity funds. The approach requires only an unbalanced panel of cash contributions and distributions accruing to limited partners, and is robust to sparse data. We decompose private equity returns from 1994 to 2015 into a component due to traded factors and a time-varying private equity premium not spanned by publicly traded factors. We find cyclicality in private equity returns that differs according to fund type and is consistent with the conjecture that capital market segmentation contributes to private equity returns.
\end{abstract}

* Andrew Ang and Bingxu Chen are at Blackrock Financial Management Inc., William N. Goetzmann, is at Yale School of Management and NBER, william.goetzmann@yale.edu, and Ludovic Phalippou, is at the Said Business School University of Oxford, ludovic.phalippou@sbs.ox.ac.uk. The authors would like to acknowledge the use of the Oxford Supercomputing Centre (OSC) in carrying out this work. Ang and Chen acknowledge funding from Netspar and the Program for Financial Studies. We are grateful for helpful comments from two anonymous referees, Jules van Bisbergen, Elise Gourier, Larry Harris, Charles Jones, Jiro Kondo, Arthur Korteweg, Stefan Nagel, Christopher Polk, Michael Roberts (the editor), David Robinson, Morten Sorensen, and participants at American Finance Association 2015 meeting, Inquire-UK, Inquire-Europe, London Business School 2015 private equity conference, NBER 2014 Chicago meeting, McGill University, Netspar, Society for Financial Studies Finance Cavalcade, World Investment Forum, Princeton University, and the University of Notre Dame. 
Andrew Ang: I have no conflict of interest to disclose

Bingxu Chen: I have no conflict of interest to disclose

William N. Goetzmann: I have no conflict of interest to disclose

Ludovic Phalippou: I have no conflict of interest to disclose 


\section{Estimating Private Equity Returns from Limited Partner Cash Flows}

June 18, 2017

We introduce a methodology to estimate the historical time-series of returns to investment in private equity funds. The approach requires only an unbalanced panel of cash contributions and distributions accruing to limited partners, and is robust to sparse data. We decompose private equity returns from 1994 to 2015 into a component due to traded factors and a time-varying private equity premium not spanned by publicly traded factors. We find cyclicality in private equity returns that differs according to fund type and is consistent with the conjecture that capital market segmentation contributes to private equity returns. 


\section{Introduction}

Private equity is a major institutional asset class and represents a significant fraction of investments by colleges, foundations, pension funds and sovereign wealth funds, among others. A major drawback of private equity for purposes of analysis is the lack of transactions-based performance measures. This greatly hampers portfolio allocation choice, which typically requires information about the risk, return, and covariance of asset classes. In liquid markets these estimates may be derived from statistical analysis of time-series returns. In contrast, most private equity time-series are based on non-market valuations or on multi-year internal rates of return broken down by fund vintage years.

The primary contribution of this paper is the introduction of a methodology based on Bayesian Markov Chain Monte Carlo (MCMC) to estimate a time-series of private equity returns using cash flows accruing to limited partners and factor returns from public capital markets. The procedure uses a similar identification strategy to that of Cochrane (2005), Korteweg and Sorensen (2010), Driessen, Lin, and Phalippou (2012), Franzoni, Nowak, and Phalippou (2012), and Korteweg and Nagel (2013). Our contribution with respect to prior research is that, in addition to estimating factor loadings and alphas we are able to construct a quarterly time-series of returns which is a useful metric for understanding the inter-temporal behavior of the asset class.

Our estimation approach decomposes returns into a component due to exposure to traded factors and a time-varying private equity premium not spanned by traded factors. The factor exposures capture the systematic risks of various classes of private equity and the time-varying private equity premium can be interpreted as an alpha orthogonal to the traded factors. ${ }^{1}$

The estimation is based on a model of private equity returns that identifies necessary assumptions and conditions for estimation. Because some of the assumptions required by the model may be violated in practice, we test its sensitivity with extensive simulations using both randomly generated data and pseudo-funds drawing on historical U.S. stock return data. We find that the estimation is robust to many violations of the assumptions but degrades when underlying asset returns are not significantly correlated to the traded factors and when idiosyncratic volatility is extremely high.

We apply the estimation procedure to quarterly cash flow data from institutional limited partnership

\footnotetext{
${ }^{1}$ We use the term "alpha" loosely here to denote a premium not captured by exposures to included factors. It may reflect a combination of actions under the control of the fund managers, as well as other factors.
} 
investments obtained from PREQIN covering the period 1996 to 2015. We construct return indices for private equity as a whole and sub-classes (venture capital, buyout). We find that the estimated time-series of private equity returns is more volatile than those measured using standard industry indices. We also find that it exhibits negligible serial dependence, in contrast to industry indices. This result is consistent with smoothing induced by a conservative appraisal process or by a delayed and partial adjustment to market prices, which often arises in illiquid asset markets (cf. Geltner (1991) and Ross and Zisler (1991)). We also find that the time-series variation in returns differs widely across sub-classes and is highly cyclical. The cycles correspond well with the time series variation in funding cycles and anecdotal evidence about peaks and troughs in performance of each of the sub-classes. This result suggests that considerable diversification can be obtained within just the private equity domain.

The second contribution of the paper is to test whether private equity returns are spanned by portfolios constructed from publicly traded securities. This has an important bearing on whether low-cost private-equity replication strategies are feasible. We find that the private-equity specific factor is significant, which shows that the private equity premium is not perfectly replicable by simple passive public-equity strategies. Our analysis of this factor suggests that part, but not all, of it is related to a proxy for illiquidity.

The third contribution of this paper is to test an economic theory about the source of private equity returns. We use the estimated total return series for buy-out funds to test a market segmentation theory, i.e. that buy-out funds add value when spreads between equity and fixed income yields are large (cf. Kaplan and Strömberg, 2009). We find support for this hypothesis: buy-out fund returns are higher when the cross-market spread is greater.

Finally, while private equity is unique in its cash flow structure and fee structure, our methodology has the potential for use in other market settings in which asset market values are infrequently observed and yield significant stream of cash flows in between these market valuations.

The paper is organized as follows. Section 2 derives the model from first principles and uses simulations to understand robustness, with a particular focus on when the methodology works well or poorly. Section 3 details the data. Section 4 presents estimation results on the risk, return and time series characteristics of private equity, and tests the market segmentation hypothesis. Section 5 concludes. 


\section{Methodology: Derivations and tests}

The intuition behind the methodology is that the present value of capital distributions is equal to the present value of capital investments when the discount rate is the time-series of the average realized returns across the set of underlying illiquid investments, i.e. the index of returns. As the minimal aggregation level we can work on empirically is a fund, which contains between 10 and 30 underlying investments, we have one moment condition per fund. As the number of funds is higher than the number of time periods, the system is over identified and we can use a maximum likelihood estimation to estimate which path the latent index of returns is more likely to have followed given the observed cash flow amounts and timing. ${ }^{2}$

In this section we derive an approach to estimating a private equity return index based on historical fund cash flows. As with all models developed for empirical application, it relies on necessary assumptions that may be satisfied or violated depending on the underlying data-generating process. We point these out and discuss how such violations may affect estimation outcomes. This offers a guideline for testing the robustness of the method in later sections. In addition, an important benefit of the derivations below is that we derive, from first principles, the Public Market Equivalent [PME] introduced by Kaplan and Schoar (2005).

\subsection{Derivation}

Consider a private equity fund which makes $N$ investments at times $t_{i}, i \in\{1, \ldots, N\}$ of amount $I_{i}$ each of which pays a single terminal dividend $D_{T_{j}}$ at times $T_{j}, j \in\{1, \ldots, N\}$. $^{3}$ We then have the following equality for each investment $i$ :

$$
D_{T_{j}}=I_{i} g_{t_{i}+1}^{i} \ldots g_{T_{j}}^{i}
$$

\footnotetext{
${ }^{2}$ One basic requirement is that at least one capital distribution occurs in each quarter, but we find that the number of capital distributions is high enough, enough during the financial crisis.

${ }^{3}$ This is without loss of generality because an investment with multiple payoffs can be rewritten as separate investments made at the same time with one payoff each. Note also that the dividend paid at time $T_{i}$ does not necessarily correspond to investment $I_{i}$. Because private equity funds hold multiple underlying portfolio companies, cash flows received by an investor cannot be assigned to underlying investments. For example, a series of cash flows [-100, 200, -100, 400] cannot be decomposed into two transactions $[-100,200,0,0]$ and $[0,0,-100,400]$ because part of the final $\$ 400$ cash flow might be due to investments made with the first $\$ 100$ paid into the fund. If it were observable, the separation into underlying investments would enable us to use standard techniques. Such a separation is generally not possible with private equity cash flow data. An exception is the dataset used by Ljungqvist and Richardson (2003).
} 
Where $g_{t}^{i}$ is one plus the rate of return of the investment during quarter $t$. Importantly, $g_{t}^{i}$ is a realized return process that cannot be directly observed; it represents neither an ex-ante expected rate of return to a given investment nor a forward-looking discount rate.

\section{Assumption 1:}

(2) $\ln g_{t}^{i}=\ln g_{t}+\epsilon_{t}^{i}$, with $\epsilon_{t}^{i}$ is i.i.d, normally distributed and independent of $g_{t}$.

This assumption is standard (see Cochrane (2005) among others). ${ }^{4} \ln g_{t}^{i}$ is decomposed into two components, one that is common across all investments (including a constant) and one that is idiosyncratic with a non-zero expectation. We denote $\operatorname{var}\left(\epsilon_{t}^{i}\right)=s^{2}, E\left(\epsilon_{t}^{i}\right)=\mu$ and set $\mu=-.5 s^{2}$; $\mathrm{E}($.$) is the expectation operator across all investments during period t$.

This assumption is violated when $\epsilon_{t}^{i}$ is not i.i.d. in the time-series. For example, the fee structure could induce autocorrelation: all investments of funds that passed their hurdle rate at time $t$ will have persistently lower realizations of $\epsilon_{t}^{i}$. We investigate this issue below using extensive simulations to understand robustness and to identify the conditions of the error terms that are most problematic. $^{5}$

From assumption (1) it follows that:

$$
E\left(\exp \epsilon_{t}^{i}\right)=\exp \left(E\left(\epsilon_{t}^{i}\right)+.5 \operatorname{var}\left(\epsilon_{t}^{i}\right)\right)=\exp \left(\mu+.5 s^{2}\right)=1
$$

Using equations (2) and (3), we have:

$$
E\left(g_{t}^{i}\right)=E\left(g_{t} \exp \epsilon_{t}^{i}\right)=E\left(g_{t}\right) E\left(\exp \epsilon_{t}^{i}\right)=g_{t} E\left(\exp \epsilon_{t}^{i}\right)=g_{t}
$$

Hence, $g_{t}$ is the expectation of gross returns across all investments by all funds during period $t$.

Econometricians cannot estimate equation (1) because the invested amount $I_{i}$ needs to be compounded from time $t_{i}+1$ to $T_{j}$ and econometricians do not know whether the first investment

\footnotetext{
${ }^{4}$ Although standard, this assumption is restrictive and potentially violated. For example, if there are two types of investments (such as some with high average returns and some with low average returns due to some risk differences), then $\epsilon_{t}^{i}$ will not be i.i.d in the cross section. This is because there is a commonality among a subset of investments that is not modelled by the econometrician. In a sense this is unavoidable (and probably why it is a standard assumption) but it is important to keep it mind, especially in a private equity context where some investments could be junior debt, leveraged equity, real estate, or early stage venture capital. These investment types are all quite different from one another but all contain a common un-modelled component within each type. Empirically, we partially capture such commonalities by running analyses on sub-samples of funds based on their type.

${ }^{5}$ Another source of autocorrelation is if different investments have different return persistence levels.
} 
is paid out at time $T_{j}$. However, we can bring each investment of a given fund to the same base date. ${ }^{6}$ Combining equations (1) and (2) we can write:

$$
\frac{I_{i}}{g_{t_{1}} g_{t_{2} \ldots} \ldots g_{t_{i}}} \exp \left(\epsilon_{t_{i}+1}^{i}+\cdots+\epsilon_{T_{j}}^{i}\right)=\frac{D_{T_{j}}}{g_{t_{1} \ldots g_{T_{j}}}}
$$

Let us denote

$$
U_{t_{i}, T_{j}}^{i}=\exp \left(\epsilon_{t_{i}+1}^{i}+\cdots+\epsilon_{T_{j}}^{i}\right)
$$

Since $\epsilon_{t}^{i}$ are i.i.d and normally distributed, $\ln \left(U_{t_{i}, T_{j}}^{i}\right)$ follows a Normal distribution. ${ }^{7}$

When we sum up equation (5) across the $N$ investments made by a fund, and using the notation in equation (6), we can write:

(7) $\sum_{i=1}^{N} \frac{I_{i}}{g_{t_{1} \ldots} g_{t_{i}}} U_{t_{i}, T_{j}}^{i}=\sum_{j=1}^{N} \frac{D_{T_{j}}}{g_{t_{1} \ldots g_{T_{j}}}}$

Let us define $P V_{-}$Div , PV_Inv and $w_{i}$ as follows:

(8) PV_Div $=\sum_{j=1}^{N} \frac{D_{T_{j}}}{g_{t_{1} \ldots g_{T_{j}}}} ; P V_{-} I n v=\sum_{i=1}^{N} \frac{I_{i}}{g_{t_{1} \ldots g_{t_{i}}}} U_{t_{i}, T_{j}}^{i} ; w_{i}=\frac{\frac{I_{i}}{g_{t_{1} \ldots g_{t_{i}}}}}{P V_{-} I n v}$

Dividing each side of equation (7) by $P V \_I n v$, and using above notations we obtain ${ }^{8}$ :

(9) $\sum_{i=1}^{N} w_{i}\left(U_{t_{i}, T_{j}}^{i}\right)=\frac{P V_{-} D i v}{P V_{-} I n v}$

The left side of equation (9) is a weighted sum of log normal distributions, which has no closed form expression. By the central limit theorem, this sum will converge to a Normal distribution but Baker and Trietsch (2013) show that the log-normal distribution is a better approximation. ${ }^{9}$

${ }^{6}$ Our data are observed by fund. Simply summing up equation (1) across all the investments in the same fund would still require econometricians to know the correspondence between cash flows. A solution is to discount each investment to the same base date as we do here.

${ }^{7} U_{t_{i}, T_{j}}^{i}$ is Lognormally distributed, with the following two moments:

$$
\begin{aligned}
& E\left(U_{t_{i}, T_{j}}^{i}\right)=\exp \left(\mathrm{E}\left(\ln \left(U_{t_{i}, T_{j}}^{i}\right)\right)+.5 \operatorname{Var}\left(\ln \left(U_{t_{i}, T_{j}}^{i}\right)\right)\right) \rightarrow E\left(U_{t_{i}, T_{j}}^{i}\right)=1 \\
& \text { and } \quad \begin{aligned}
\operatorname{Var}\left(U_{t_{i}, T_{j}}^{i}\right)=\left[\exp \left(\operatorname{Var}\left(\ln \left(U_{t_{i}, T_{j}}^{i}\right)\right)\right)-1\right] \exp \left(2 E\left(\ln \left(U_{t_{i}, T_{j}}^{i}\right)\right)+\operatorname{Var}\left(\ln \left(U_{t_{i}, T_{j}}^{i}\right)\right)\right) \\
\rightarrow \operatorname{Var}\left(U_{t_{i}, T_{j}}^{i}\right)=\exp \left(\left(T_{j}-t_{i}\right) s^{2}\right)-1
\end{aligned}
\end{aligned}
$$

\footnotetext{
${ }^{8} \mathrm{We}$ work with the ratio rather than the difference because the ratio has the advantage that it is robust to different periods used to compute the present values. That is, if the valuation date is taken to be the first date of the sample, then present values of cash flows for funds formed at the end of the sample are smaller than present values of cash flows for funds started at the beginning of the sample. Taking a ratio removes these timing effects.
} 
Assumption 2: As $N$ goes to infinity, no single component should dominate. In our case, this is equivalent to

(a) $w_{i} \rightarrow 0$, when $N \rightarrow \infty$ (no dominantly large investment)

(b) $\frac{\left(T_{j}-t_{i}\right)}{\sum_{j}^{N}\left(T_{j}-t_{j}\right)} \rightarrow 0$ (no dominantly long investment)

Under these two regularity conditions, we can apply the lognormal central limit theorem of Baker and Trietsch (2013): ${ }^{10}$

(10) $\frac{P V_{-} D i v}{P V_{-} I n v}=\sum_{i}^{N} w_{i}\left(U_{t_{i}, T_{i}}^{i}\right) \cong u$,

where

(11) $\ln (u) \sim$ i.i.d. $N\left(-0.5 \sigma^{2}, \sigma^{2}\right)$, and $\sigma^{2}=\ln \left[\sum_{i}^{N} w_{i}^{2} \exp \left(\left(T_{i}-t_{i}\right) s^{2}\right)\right]$

Let us denote variables associated with fund $h$ with a subscript $h$. We have the following equality for each fund, which we refer to as the Present Value Ratio [PVR]: ${ }^{11}$

(12) $\mathrm{PVR}_{\mathrm{h}}=\ln \frac{P V_{-} D i v_{h}}{P V_{-} I n v_{h}} \cong \ln u_{h}$, where $\ln u_{h} \sim N\left(-0.5 \sigma_{h}^{2}, \sigma_{h}^{2}\right)$.

Note that, if the time-series $g_{t}$ equals the rate of return of the S\&P 500 index, PVR is exactly the PME of Kaplan and Schoar (2005). ${ }^{12}$

\footnotetext{
${ }^{9}$ The sum of independent random variables that have non-zero means (such as log-normal distributions) converge very slowly to a Normal distribution. In particular, an extensive literature shows that the sum of log-normal distributions remains close to a log-normal distribution (e.g. Fenton (1960), Barakat (1976)). This is why the log-normal distribution is sometimes said to be 'quasi-permanent'. Most recently, Baker and Trietsch (2013) formally introduced the 'lognormal central limit theorem.' They show that the log-normal distribution is a better approximation than the Normal for the sum of a few strictly positive random variables, even if the summands are not i.i.d., provided that the summands satisfy two regularity conditions.

${ }^{10}$ We invoke an asymptotic result here. Given that each fund has at most about twenty investments, asymptotic results are unlikely to be accurate in our context. Using Monte Carlo simulations, we are able to compare the empirical distributions of $\ln u_{h}$ with the best-fitting Normal distribution. Formal tests of Normal distribution reject the null that the empirical distribution is Normal but the violation is economically small (shown in internet appendix). Thus, this error will play a role in the precision of our estimation procedure and will be quantified in the next section (when we compare our estimated private equity time-series to the true one in various settings).

${ }^{11}$ We work with the log transformation to lower the effect of outliers in the estimation.

${ }^{12}$ Our derivation can be seen as a formal proof of the proposition in Kaplan and Schoar (2005) that if a fund has a PME that is unity when using realized S\&P 500 returns as $g_{t}$, then investors are indifferent between investing in a private equity fund or in the S\&P 500 index.
} 
As $\sigma_{h}^{2}$ is not a priori identifiable, we need to make a Homoscedasticity assumption:

Assumption 3: The volatility of $\ln \frac{P V_{-} D i v_{h}}{P V_{-} I n v_{h}}$ is the same for all funds: $\sigma_{h}^{2}=\sigma^{2} \cdot{ }^{13}$

Our strategy is to filter the private equity returns $\left\{g_{t}\right\}$, such that the conditions in equation (12) are satisfied across funds and across time. Equation (12) represents an observation equation and the returns are latent parameters.

As is standard in the literature, we assume that the state equation for the latent returns (a.k.a. the equation of motion) is a function of a set of common factors, plus an uncorrelated observation error in the observation equation.

Assumption 4: The state equation dynamics of the filtering problem are as follows:

(13) $g_{t}=\alpha+\beta^{\prime} F_{t}+f_{t}+r_{t}^{f}$

Where, $F_{t}=\left[F_{1, t}, \ldots, F_{J, t}\right]$ is a set of $J$ common tradable factors, which are observable in public markets. ${ }^{14} \beta$ contains the loadings on the common factors, $F_{t} . \alpha$ reflects the average level of private equity returns in excess of its systematic (and liquid) component of the private equity return. $f_{t}$ is an asset class-specific latent factor with mean zero orthogonal to the traded factors, $F_{t}$. This potentially makes private equity non-redundant in the space of tradable assets. ${ }^{15}$

We estimate the model using a Bayesian MCMC procedure described in the Appendix. We treat the unobserved returns as parameters to be estimated (referred to as "data augmentation"), along with the other parameters of the data generating process.

\footnotetext{
${ }^{13}$ Assumption 3 is valid when funds have similarly concentrated portfolios, and when their investments have similar holding periods and idiosyncratic volatility. This can be violated by a variety of conditions (e.g. significant leverage differences across investments). Note also that if assumption 1 is violated then assumption 3 is violated as well.

${ }^{14}$ We consider factors like the Fama and French (1993) factors.

${ }^{15}$ Assumption 4 states that the cash flows associated with any investment are generated by a time-varying portfolio of assets that have unobserved but continuous latent values. We assume returns are a linear function of an underlying systematic factor structure. Thus, if the latent asset values were observable, some portion of their return variance could be explained by common factors using standard regression methods. The latent factor process, $f_{t}$, can be viewed as the idiosyncratic component of private equity returns. We can specify it as an $\operatorname{AR}(1)$ process to reflect the fact that the $f_{t}$ process is not exposed to the forces of arbitrage because, by design, it is not tradable and is orthogonal to factors in the public markets. $f_{t}$ may be persistent because of persistent aggregate manager skill, the inter-temporal variation in good investment opportunities or the trends in performance due to non-constant returns to scale. However, in simulations, we find that with time-series that are shorter than 100 time periods (as is the case in our empirical section) we cannot estimate this autoregressive parameter with a reasonable degree of precision. As a result, we specify $f_{t}$ as an i.i.d. standard normal distributed process in the analysis and simulations below.
} 


\subsection{Further discussion on the methodology}

We specify error terms as log ratios of summed discounted cash flows and minimize one large error term per fund in the estimation process. Problems may arise from this aggregation due to intertemporal compounding and cross-correlations. Specifying the price path of errors for individual funds (other than as i.i.d.) is intractable, rendering our above simplification necessary for estimation. The degree to which this specification influences estimation outcomes is ultimately an empirical question and motivates the extensive simulations detailed in section 2.3 below.

There are several additional caveats to our approach. First, a natural interpretation of the index is that it is the net return to investing in each of the private equity funds in the database. This interpretation implicitly assumes that the returned capital $D_{t}$ in any given period is immediately reinvestable in all existing funds as opposed to only new funds. This is typically not the case. This assumption, however, only affects the interpretation of the premium factor - the latent factor component, $f_{t}$, of the total return index. The passive component due to $\beta^{\prime} F_{t}$ comprises only marketable factors, in which investors can re-invest or rebalance.

A second caveat is that, by presuming that the passive component is accessible to an investor, we are also implicitly assuming that leverage may be used to achieve a factor exposure greater than one. Note that this caveat also applies in any studies using linear factor exposures. As we show below, some of the variation in the PE return series is explained by large exposures to public equity factors. Private equity may provide a means to relax borrowing constraints and this convenience may be priced (cf. Frazzini and Pedersen (2014)). We also use long-short factors, and implicitly assume that short-selling is feasible and costless in replicating the performance of such factors.

Third, our procedure solves for the best fit of the private equity returns given fund cash flows. We are not solving for expected returns, but for estimates of realized private equity returns. We take the cash flows as given to solve for the realized returns. To obtain estimates of forward-looking discount rates, we need to embed an expectation process into a valuation model and tie the discount rates to estimates of our realized returns. This is an interesting research topic but our current goals are more modest. ${ }^{16}$

\footnotetext{
${ }^{16}$ Recent work by Jagannathan and Sorensen (2015) and Korteweg and Nagel (2015) explore the relation between PMEs and discount rates. The problem of correlated forward-looking discount rates and cash flows is also considered by Brennan (1997) and Ang and Liu (2004).
} 


\subsection{Simulations}

Before applying our methodology to real data, we investigate how it performs under known conditions. We generate cash flows whose true, underlying returns are generated by standard processes, which we use to form hypothetical funds and then filter $g_{t}$ using our methodology. These simulations provide useful guidance on accuracy under various scenarios. Through the appropriate use of priors and some parameterization of the return process, the procedure can handle sparse data and unbalanced panels of contributions and distributions. Yet the precision of our approach depends on the properties of the true data generating process, especially in small samples.

\subsubsection{Simulations when the error structure is as specified in our model}

Using simulated panels of private equity cash flow data, we determine whether we can recover unbiased estimates of the realized returns on a population of private equity funds. We simulate our model with the error structure described in equation (12) and the following parameters:

1. The gross return at date $t$ is given by $g_{t}=1+\alpha+\beta \cdot R_{t}^{M}+f_{t}$; where $\alpha=4 \%$ p.a. and $\beta=1.5$ (the risk free rate is zero).

2. Factor returns $R_{t}^{M}$ are iid and drawn from a Normal distribution with an annual mean of $8 \%$, and an annual volatility of $20 \%$.

3. The time-series of $f_{t}$ is drawn from a normal distribution with mean 0 , and volatility of either $1 \%$ or $10 \%$. In the latter case, the resulting (true) net return $\left(g_{t}-1\right)$ has a mean of $16 \%$ and a volatility of $32 \%$ p.a.

We consider a population of 500 funds with five investments each and 80 quarters of data. Each quarter, several \$1 investments are started in each fund and the value of the investment grows at a rate of $g_{t}$ in quarter $t$. Each investment is sold following a simple rule: each quarter, one in $x$ investments is sold. In all but the first set of simulations (case 1) $x$ is set to 28; this means that investments cannot last more than seven years and thus funds cannot last more than 12 years (since the last investment occurs in year 5). All investments not liquidated at the end of the sample (year 20) are terminated at that time. 
Panel A of Table 1 shows the results from the simulations and documents the effects on summary statistics, correlations to the true index, and the mean squared error. We first consider a simple case: investments are held for two quarters on average and the standard deviation of the PVR across funds is $\sigma_{h}^{2}=1 \%$ (referred to as idiosyncratic volatility). For each of the following cases, we incrementally add additional 'handicaps' to our simple estimation. Case 2 increases the average holding period to 3.5 years. Case 3 increases idiosyncratic volatility to $10 \%$ (which matches the empirical distribution of PVRs in our dataset). Case 4 increases the number of investments per fund from 5 to 20. Case 5 shows results when the error term is uniformly distributed instead of $\log$ normally distributed. Finally, Case 6 has the wrong priors (prior on alpha is zero and prior on beta is one), in addition to all of the previously considered 'handicaps'.

Table 1 shows that in the first 'simple' case, we retrieve the correct values of the parameters' mean, and standard deviation, and that the average correlation between the true time-series and the estimated time-series is high: $98.7 \%$. Panel B of the Table shows the $25^{\text {th }}, 50^{\text {th }}$ and $75^{\text {th }}$ percentiles of the simulated distributions for two parameters of interest: alpha and beta. Note that even in this simple case, while the median value is unbiased, there is significant variation in both the annual alpha and the market beta, which shows that it is difficult to retrieve a precise estimate of factor loadings.

\section{$<$ Table 1 >}

As we add one handicap each time, the precision - as measured by the correlation to the true index clearly declines. It changes from $98.7 \%$ in the simple case to $94.5 \%$ in the case that includes all handicaps. We also note that the median alpha is no longer equal to the true value (but the difference is small). In the sixth case, with diffuse priors, the estimated $\beta$ is lower than the true $\beta$, which reduces the volatility of the systematic factor component, but the estimated mean performance is not far from the true one. ${ }^{17}$ The correlation between the true time-series of returns and the estimated time-series of returns remains high.

In sum, Table 1 shows that if the data generating process has the assumed final structure (equation (12)) then the methodology retrieves a reasonable correlate of the time-series of true returns. However, the estimation of alpha and factor loadings is less precise and influenced by the prior.

\footnotetext{
${ }^{17}$ The volatility of $f_{t}$ mechanically increases to match the specified moment condition, but it does not increase enough. As a result, $\alpha$ is too high (since $\beta$ is too low).
} 


\subsubsection{Simulations when investments are listed stocks}

To evaluate the robustness of our approach to the nature of the true (but unknown) equity return generating process, we simulate panels of cash flows where private equity funds randomly buy and sell actual, listed stocks. We begin with a simple setup. We take listed stocks from 2001 to 2010. During that time period the value weighted stock market index (our factor) had overall returns close to zero. In contrast the equally weighted stock index had high and more cyclical returns. If we simulate private equity funds investing in listed equity, our $g_{t}$ time-series should look like the CRSP equally weighted index.

Specifically, we take all U.S. common stocks with ten years of valid monthly data in CRSP (2001 to 2010). This simplification has the advantage of avoiding holes in the return series. There are 3,120 stocks from which we form 624 funds, with five investments each. Each fund starts at the same time and is liquidated in ten years later. We apply our algorithm and use a single factor model with the CRSP Value Weighted (CRSP-VW) as the factor. We compute a "true" index [C-EW], i.e. the equal-weighted stock index constructed from the 3,120 stocks. The CRSP Equally Weighted index (CRSP-EW) has a slightly higher average return and volatility than C-EW because our data restriction dropped small and infrequently traded stocks. Nevertheless, the two indices are quite close.

The cash flows are generated as in the other simulation setups: each fund makes one investment per year for five years. Each quarter, 1 in 24 investments across all of the funds are liquidated in order to have all funds fully liquidated by the end of year 10 . We have an unbalanced panel of cash flows similar to that observed in practice and we know the true underlying index return series.

Figure 1 summarizes the results. The left figure compares the average time-series of estimated returns (blue dashed line) and true returns (black solid line). Untabulated results from this simulation show that we retrieve the correct mean but we underestimate volatility by $3 \%$ p.a.. Our estimated time-series has a $92 \%$ correlation with the observed equally weighted stock-market index on average. By construction, there are fewer observations, and thus the average series has a greater deviation at the beginning. The average correlation goes up to $95 \%$ if we remove the first year of our estimated time-series. 
The right panel on Figure 1 shows the cumulative log return of the true and mean estimated return series as well as that of the CRSP Value Weighted index (dashed red), and CRSP Equally Weighted index (astered green) when the first year is removed. The factor (CRSP-VW) is flat throughout that decade, which reflects the well-known 'lost decade' for value-weighted stock indices. In contrast, we see strong cycles in the equally weighted stock indices (CRSP-EW and C-EW). The estimated return series' recovers these cycles well.

\section{$<$ Figure $1>$}

\subsubsection{Simulations to identify problem zones}

Using actual stocks to simulate data has important benefits: it is reasonable to assume that underlying private equity investment returns - particularly for buyout funds -- resemble those of individual stocks, such that their underlying return dynamic is different from the one we assumed. However, the downside of this approach is that we cannot vary certain key parameters. In this subsection we change different parameters to determine zones in which our method performs less well.

We now simulate data from equation (2) rather than equation (12). Accordingly, instead of having errors distributed around PVRs, we have errors added to each return each quarter for each investment. This way we can change the idiosyncratic volatility of these errors $\left(\sigma_{\varepsilon}\right)$ to assess whether the econometrician working with equation (12) out of necessity is still doing a good job when the assumptions we made in section 2.2 are violated.

Equation (12) will hold less precisely empirically as $\sigma_{\varepsilon}$ increases because the convergence of the summation of the error terms will be slower, which should generate a small sample problem. Other variables that affect total volatility should also affect estimation precision. As in the simulations above, we work with a one factor model. In such a setup, total volatility is affected by three elements: Beta, PE-specific risk $\left(\sigma_{f}\right)$ and idiosyncratic volatility. Our return time-series $(\mathrm{g})$ is decomposed between a systematic component $\left(\beta \cdot R^{M}\right)$ and a PE-specific component $(f)$. The question is how these three volatility drivers affect each of the two return components.

Figure 2 shows the resulting correlations between the true time series of returns and the estimated returns plotted against different levels of idiosyncratic volatility. Panel A shows the precision of the estimation of the total return time-series $(g)$ as a function of both the idiosyncratic volatility $\sigma_{\varepsilon}$ and the private equity specific 
volatility $\sigma_{f} .{ }^{18}$ When $\sigma_{\varepsilon}$ increases from negligible to very large (150\% p.a.) the correlation between the estimated and the true time-series always decreases, but the decrease seems relatively modest.

Panel A also shows the effect of changing $\sigma_{f}$ on the relationship between correlation and idiosyncratic volatility. Panel B shows the same effect but for changing $\beta$ instead of $\sigma_{f}$. Even though both $\sigma_{f}$ and $\beta$ increase total volatility, they have the opposite effect on estimation precision (i.e. correlation). Increasing $\sigma_{f}$ decreases precision, while conversely increasing $\beta$ increases precision. When both idiosyncratic volatility and $\sigma_{f}$ increase, the correlation decreases but remains reasonable.

Figure 2 - Panel B shows the impact of large changes in $\beta$ by setting it equal to $0.75,0.33$ and 0 respectively. The latter case is equivalent to running the analysis without any factors. Here the effect is dramatic and the correlation decreases quickly. When beta is below 0.33 , and idiosyncratic volatility is above $20 \%$, the correlation goes below $50 \%$. We still recover part of the true time-series (correlation is statistically different from zero), but the economic magnitude is much smaller. ${ }^{19}$

The reason for this is that retrieving the systematic return component is easier than retrieving the PE-specific one. The PE-specific component is a pure random variable that we generate and the code needs to recoup it, while we impose a prior for the systematic part which restricts the search space. Even if this prior is wrong (see Figure 2 - Panel C) the estimated time-series is highly correlated with the true variation. ${ }^{20}$

If the factor loadings (i.e. the estimated $\beta$ ) are low, then returns are largely comprised of a pure private equity component and idiosyncratic risk. Hence it is more difficult to retrieve total returns and correlation falls quickly even though total volatility is going down.

We can confirm this insight by computing the correlation between the true and estimated PE-specific return component only $(f) .^{21}$ If we repeat the graphs in the first three Panels, the three lines overlap one another, i.e. there is no change as a function of $\sigma_{f}, \beta$, and error in the prior on $\beta$. For this reason, we do not tabulate it.

\footnotetext{
${ }^{18}$ Recall that $\sigma_{\varepsilon}$ is the volatility (annualized) of the shock added each quarter to each investment return.

${ }^{19} \mathrm{We}$ also run simulations with varying priors on beta which we report in the internet appendix. We find that changing priors has a limited impact on correlation. We also find that estimates of beta and volatility are biased when we combine variations of different parameters: level of volatility, true beta, and wrong/right priors. When the prior on beta is too low, the estimated beta remains below the true beta. When incorrect priors are combined with high volatility and a low true beta we estimate a beta that is only half of the true beta. Volatility is also significantly underestimated in this case.

${ }^{20}$ To elaborate, we generate Beta*Rm, where $\mathrm{Rm}$ is the same for the simulation and in the estimation. Therefore, even if our beta prior is wrong, given that the model is right, the correlation will still be high.

${ }^{21}$ Note that this is equivalent to setting beta to zero and look at the correlation between true and estimated $\mathrm{g}_{\mathrm{t}}$ as done above.
} 
The right hand side of Figure 2 - Panel D shows the correlation between the true and estimated PE-specific return component only $(f)$ for varied sample size. We see clearly the dramatic impact of idiosyncratic volatility on estimation precision. Idiosyncratic volatility mainly affects the PE-specific return estimation: the higher it is, the more difficult it is to isolate and recoup the PE-specific component. It does not have much impact on the estimation of the systematic component (left hand side of Figure 2 - Panel D). It is for this reason that as idiosyncratic volatility rises, correlation between total returns decreases only modestly. ${ }^{22}$

Panel $\mathrm{E}$ is similar to Panel $\mathrm{D}$, but instead considers the impact of varying the sparsity of the cash flow matrix (i.e. by changing average holding period) instead of number of funds. Similarly, the effect on the total return correlation is minor, but the effect on the PE-specific return estimates is large.

Notice that in terms of statistical significance, which is commonly used to assess econometric success, all correlations are statistically different from zero. For example, $p$-values are less than $1 \%$ when correlation is $10 \%$. For the cases in which we chose extremes in parameters, correlations are always positive and significant at a $1 \%$ level test. Where $\sigma_{f}$ is $30 \%$ and $\beta$ is 1.5 , the volatility of the private equity market index is $\sqrt{1.5^{2} \sigma_{m}^{2}+\sigma_{f}^{2}}=42.4 \%$, which is more than twice the volatility of the S\&P 500 index. Idiosyncratic volatility of $150 \%$ for a private equity investment is also very high.

Overall, our results show that we cannot recover the latent time-series for an asset class that has small exposures to specified factors. This suggests that our methodology is less useful for estimation of an index built from unusual alternative asset classes such as collectibles, for example, unless relevant factors can be identified.

\section{$<$ Figure 2 >}

In the internet appendix we show results from eleven different economies, where we vary the number of investments per fund, introduce a regular dividend and other changes of interest. Results are found to be robust to most changes with the exception of introducing a 'hold-on-tolosers' rule. As seen from the derivations above, inter-temporal independence is an important assumption. If investments are more likely to be monetized when they have performed better, the independence assumption is violated. However, the correlation between the true and estimated time-series remains economically reasonable at about $90 \%$.

\footnotetext{
${ }^{22}$ Note that the decay in precision is not overly sensitive to the number of funds in the sample.
} 


\subsubsection{Simulations on post fee return series}

The existence of a complex, non-linear fee structure (see Metrick and Yasuda (2010)) for managed assets such as private equity funds affects the precision of our estimation approach. More subtly, when a complex fee structure is to be modelled, 'true' fund returns for a given investment by a fund can be defined in three ways:

1) Cash. The modeler may treat fees on a cash basis. In this approach, the return on an investment is the realized difference between the purchase and sale price net of intermediate cash flows minus paid-out carried interest upon exit, and the management fees paid to the fund (calculated pro-rata across on-going fund investments). This approach does not capture unrealized fees for past performance or the contractual option value of future fees.

2) Accrual. This method accrues fees based upon paper gains in the portfolio value to the current date. This approach is common in the hedge fund industry where $20 \%$ incentive fees and high water market provisions are common. Hedge fund databases typically report returns on a monthly basis, while incentive fees are paid on a quarterly or annual basis, conditional upon meeting a prespecified hurdle. Incentive fees are accrued on an interim monthly basis until they are realized at the end of the fee determination period. This approach captures unrealized fees but ignores the contractual option value of future fees. For hedge fund, the $20 \%$ incentive fee clearly has value prior to the end of the fee determination period, even when it is out of the money - i.e. no fee has been accrued, (see Goetzmann, Ingersoll, and Ross (2003)).

3) Mark to Market. This method treats the management fees and carried interest as a call option on each investment, accrues it in the period the investment is made and revalues it each period as conditions change. Metrick and Yasuda (2010) pioneered this approach to private equity valuation by taking the discounted expected future fees with respect to the risk-neutral pricing kernel. While not commonly in use in practice, the utility of marking manager fees to market is obvious. GP actions that increase the value of the fee at the expense of the LP may affect other variables of interest such as covariance with the market.

Because we have ex-post realized cash flows from LPs, we are unable to estimate private equity indexes based on either an accrual or a mark-to-market basis. It is therefore important to study the effects of this limitation on outcomes. Throughout our derivations, $R_{t}$ is the return per quarter net of fees irrespective of the fee structure. However, if true returns are defined so that they continuously account for changes in the expected carried interest to be paid at exit (the mark-to-market case), this affects the true beta of the LP investment and 
therefore our index. Furthermore, any fee structure will generate some autocorrelation in residuals and thus affect the 'true' unobservable returns in a predictable fashion. In particular, at the beginning of our return series, the true return will be lower due to higher management fees - often referred to as the J-curve effect.

Choi, Metrick, and Yasuda (2012) point out another potential problem in estimating the dynamics of LP returns. Because fees are non-linear returns to the underlying asset, when the market goes up, the LP payoff will be concave. It follows that the beta of LP returns will be lower when the market is up and higher when the market is down because fees are not being earned. ${ }^{23}$ Finally, if a fund has strong past performance, then all future payoffs will be subject to carried interest, which will also generate autocorrelation in the error term, as well as a non-linear market exposure. ${ }^{24}$

To address these potentially problematic issues, we perform two types of simulation.

Case 1: We simulate a whole-fund waterfall (also called European waterfall) following Sorensen, Wang, and Yang (2014), and Choi, Metrick, and Yasuda (2012). In this case, we also have a carried interest charged on all exited investments once the fund passed the $8 \%$ hurdle rate and we incorporate a $100 \%$ catch up provision.

We allocate the management fees each quarter to each investment that is alive within a fund (equal allocation across investments) and the carried interest that is retained from the distribution of each investment (as done in practice). We then have a J-curve effect: at the beginning of the fund's life post-fee returns are much lower than pre-fee returns because of the management fees.

This quarterly error term is not modelled by the econometrician; instead the error term in the econometric model is on the Net Present Value of funds (equation (12)). As above, returns are generated with a one factor model with a true $\beta$ of $1.5, \alpha$ of $4 \%$ p.a., plus a mean zero PE-specific return with $20 \%$ annual volatility plus idiosyncratic

\footnotetext{
${ }^{23}$ We examine this non-linearity by regressing our Buyout index $g_{t}$ on stock-market returns [not reported], and we find that our estimated index captures at least part of the non-linearity predicted by Choi, Metrick, and Yasuda (2012). As we are interested in constructing an after-fee index of PE performance, we are pleased that this non-linearity is captured in the estimate. That is, the non-linear fee structures and implicit timing behavior about underlying payouts of private equity are indeed reflected in our estimated PE return series.

${ }^{24}$ Another consideration is that beta can differ across funds with some time-indexed commonality - for example a dramatic increase in market values or a shift in market volatility. In particular, funds with similar age and past performance could have a similar beta due to correlated, market or industry-specific investment opportunities. Since we do not model this, our precision will be affected. It is roughly equivalent to running an OLS regression when errors are heteroscedastic. But, as with heteroscedasticity in a regression setup, adjustments pay off only to the extent that we know something about the underlying source of heteroscedasticity. Fully deriving and modeling the private equity fee structure-induced heteroscedasticity is clearly a promising area for future research and it may require a different kind of database to thoroughly study it. In this paper we simply assess the loss in precision due to a mark to market fee return perspective.
} 
volatility. There is no autocorrelation is residuals; average holding period (duration) is 3.5 years; and the prior on $\beta$ is correct. The sample contains 600 funds that make 20 investments each.

We plot the results in Figure 3 - Panel A. It is the same format as the previous figure. Adding only the carried interest does not greatly affect correlations. However, the J-curve effect reduces average correlation significantly. But idiosyncratic volatility has little impact on average correlation once idiosyncratic volatility is above $33 \%$ p.a.. ${ }^{25}$

Case 2: In this case we compute for each investment, in each quarter, the value of the carried interest and deduct that from the market value of the investment. That is, we are marking to market the investment every quarter net of latent fees. As detailed in Metrick and Yasuda (2010), this option-based fee calculation is rather complex and requires numerical solutions. Redoing their one-time calculation for each of our investments, each quarter, in each simulation, is not feasible. However, given that our objective is to see how resilient our method is to incorporating embedded call option values rather than obtaining a realistic number, we adopt a simpler approach. $^{26}$

For each investment and each quarter, we calculate the Black-Scholes value of a call option given investment return volatility, the investment value at that point in time, and the remaining time until exit. $20 \%$ of the value of this call option (with a strike price set to investment cost) is the 'unrealized' carried interest. We track the quarterly changes in 'unrealized' carried interest, which is what we then subtract from the investment value each quarter. When the investment is exited we compute the carried interest due and then subtract the balance of the difference between the unrealized and the realized carried interest from the final dividend. We set management fees to zero here because, as shown above, management fees have a distinct effect on estimation precision.

These simulations imply a lower true $\beta$ : it decreases from 1.50 to $1.37,1.23$, and 1.08 when carried interest is $10 \%, 20 \%$ and $30 \%$ respectively. This is because the true $\beta$ is computed from the market value of the fund each quarter, net of changes in the value of the call option. The cash flows, however, do not reflect this smooth process. We therefore overestimate $\beta$ in this setup. For example, with carried interest of $20 \%$, we overestimate beta by $9 \%$, but volatility remains well estimated (non-tabulated).

\footnotetext{
${ }^{25}$ The internet appendix shows biases in estimated parameters. Management fees bias $\beta$ downwards. When both fees are present the bias in beta is more pronounced (11\% underestimated; third line in Panel A). Biases in volatility follow a similar pattern.

${ }^{26}$ The value of the option in practice is extremely complex because you need to assume a correlation between the investments done by a given fund. In addition, the payoff has different values as a function of investment value and fund value due to the catch up provision (it is a combination of options). Also, the exit timing of each investment in the fund is endogenous and inter-dependent. If we need to solve this at each point in time, for each investment, in each simulation the problem becomes impossible to simulate. Future work may incorporate these option values into our framework.
} 
Figure 3 - Panel B plots the correlation between the true and estimated return time-series. We show results for different levels of carried interest and, as in the other figures, plot correlations as a function of idiosyncratic volatility. Correlations are lower as carried interest increases, but the decrease in precision appears to be economically small.

To summarize, if we set the true return process net of fees so that fees affect an investment return only during the quarter in which they are charged, we underestimate beta. By contrast, if we set the true return process net of fees, so that fees are continuously deducted from the true investment value, we overestimate beta. In both cases, the correlation between true and estimated returns falls moderately.

\section{Data}

Preqin collects the quarterly aggregated investments, distributions, and Net Asset Values (NAVs) made by private equity funds as recorded by U.S. pension funds and obtained via routine Freedom of Information Act requests. We use the cash flow dataset of Preqin as of October 2015 with data stopping in June 2015 (there is a reporting time lag). As Harris, Jenkinson, and Kaplan (2015) we focus on the sub-set of funds that are US-focused.

The Preqin cash flow dataset is increasingly used in academia. A recent example is a first study on the secondary market for private equity fund stakes by Nadauld et al. (2015). The attraction of Preqin data is that it is publicly available (at a cost) and cash flows should be accurately reported and without a performance bias: pension funds would face serious sanctions if they deliberately misreport or only selectively report returns. Data from Burgiss, used in Harris, Jenkinson, and Kaplan (2013) and Harris, Jenkinson, and Kaplan (2015) are also increasingly used and generally perceived as more comprehensive and perhaps more accurate.

As Preqin and Burgiss are both increasingly used in academic research, we contrast average performances derived from each of these datasets. By the same token, we want to make sure that our performance figures are consistent with what would be derived in a more comprehensive dataset. Coverage in both datasets jump up in 1994 (e.g. there are less than 10 buyout funds raised in any year before 1994 in both the Burgiss and the Preqin dataset). To assess the risk profile of funds, we need to observe the cash flows of a sufficient number of funds at any point in time, and thus start with vintage 1994. We stop with vintage 2008 because less funds are raised after that and these funds have significant unrealized value as of 2015. 
The Table 5 in Harris, Jenkinson, and Kaplan (2015) shows Public Market Equivalents per vintage year for buyout and venture capital funds. In our Table 2, we copy the Harris, Jenkinson, and Kaplan (2015) figures and compute the corresponding statistics for the Preqin dataset. The output statistics are extremely close.

Funds serving fiduciaries such as pension funds report their audited calculations of portfolio value (NAV) every quarter. FASB 157 now requires fund assets to be fair market-valued, however the private nature of these investments and varying methodologies for evaluation leaves significant uncertainty. Ultimately, reported fund NAVs represent each fund manager's opinion about the assets in his or her portfolio. ${ }^{27}$ As we select funds that are seven years old or more, this issue has a moderate impact on our results but we ought to bear this in mind when trying to assess the underlying 'true' returns.

\section{$<$ Table $2>$}

\section{Empirical Results}

\subsection{Factor exposures and private equity premium}

In Table 3, we report parameter estimates of the factor loadings, $\beta$, and the $\alpha$ coefficients with different asset pricing factor models. The table reports posterior means and standard deviations of the parameters. The internet appendix offers details on the methodology, the choice of priors, and robustness checks.

We begin with models that rely on one, three, and four systematic factors. The one factor model is the CAPM; the three-factor model is from Fama and French (1993), which adds SMB and HML factors; and the four-factor model is that of Pástor and Stambaugh (2003), which adds a liquidity factor. Next, we report results for a one-factor model for which we use the CRSP equally-weighted (EW) index instead of the CRSP value-weighted index as a measure of market returns. This is equivalent to the assumption that private equity funds acquire companies that are drawn from a pool resembling the CRSP sample. That is, they are as likely to acquire a firm from the bottom decile as

\footnotetext{
${ }^{27}$ The process typically involves a valuation committee and for audited funds, the additional valuation assumptions made by the auditing firm. Brown, Gredil, and Kaplan (2015) find that fund valuations are conservative except when follow-on funds are raised. In times of fundraising, Barber and Yasuda (2016) estimate that NAV is exaggerated by about $3 \%$ for buyout funds and about $5 \%$ for venture capital funds. We run some robustness tests by applying discounts to the final NAVs reported by GPs who were fundraising in June 2015 and by excluding funds with a high ratio of final NAV to capital committed. But these changes do not affect our empirical results (non-tabulated).
} 
from the top decile of capitalization. This assumption is useful because the typical company purchased by a private equity fund is relatively small compared to the universe of listed companies. The drawback is that the equal-weighted CRSP index is not investable.

We then create three models with only traded factors. The four factors are, respectively, Vanguard S\&P 500 index minus the risk free rate, DFA microcap mutual fund minus Vanguard S\&P 500, DFA value mutual fund minus Vanguard S\&P 500, and T. Rowe High Yield minus Vanguard S\&P 500. DFA microcap proxies for the small stock premium, DFA value proxies for the value premium, and T.Rowe High Yield proxies for the liquidity premium. In order that these factors can be treated as premiums, the S\&P 500 is shorted from all but the first factor. In practice shorting the S\&P 500 is feasible and bears a negligible cost.

Finally, we show results with the new Fama and French (2015) five-factor model, which includes "profitability" and "investment" as defined by Kenneth French's website.

Table 3 shows that the CAPM estimate of the beta of private equity is 1.4 , which is unchanged using an EW market index. The estimates for the four-factor loadings on market, size, value, and liquidity factors are 1.5 for the market excess return, 0.8 for SMB, -0.1 for HML, and 0.5 for the liquidity factor. In the four-factor model, the posterior means of the market and SMB loadings is statistically significant, but this is not the case for the value and liquidity factor loadings. Nevertheless, the economic magnitude of 0.5 for the liquidity factor beta is relatively large.

Alpha is annualized and defined as the constant that makes the average value-weighted PVR equal to one, given the estimated risk loadings. Across all models, alpha is close to zero.

For the subset of venture capital funds (Panel B), alphas are mostly negative across the different models. We note that venture capital has a significant negative loading on the Fama-French value factor, which is what we would expect from a strategy of buying high-growth companies. Venture capital strategies appear to load positively on growth stocks which had low average returns. Also, the value-weighted stock-market index used in the CAPM had low returns over our sample period, which sets a low bar in terms of performance. When the index is the Equally Weighted Nasdaq Index, venture capital exhibits a significant negative alpha.

For buyout funds (Panel C) alpha is $4 \%$ annually and beta is 1.25 . This means that performance metrics reported in the prior literature are validated here. Benchmarking buyout funds to a listed 
equity benchmark without adjusting for beta seems reasonable (Robinson and Sensoy (2013), Harris, Jenkinson, and Kaplan (2013)). Our alpha with the one (value-weighted) factor model is $4 \%$, also similar to that reported in the literature. However, alpha goes to zero when we control for other risk factors. These results are those of Stafford (2016) and Phalippou (2013) among others.

The coefficients on the value and liquidity factors are positive and significant. The inclusion of the Pástor-Stambaugh liquidity factor seems to have the greatest effect on alpha - reducing it from $1 \%$ to $-3 \%$. This can be interpreted as buyout funds harvesting a liquidity risk premium in the PástorStambaugh sense that buyout funds have exposure to a liquidity factor constructed from publicly traded equities (cf. Franzoni, Nowak, and Phalippou (2012)).

In several specifications we reject the null that private equity assets are redundant with respect to the standard Fama-French and Pástor-Stambaugh equity factors. These systematic factors capture a large portion of the total returns to investing in private equity. This, however, does not necessarily imply that there is no value to private equity, because none of these equity factor returns are available without incurring transaction costs. An open question is whether an investor can cheaply access the premiums of the tradable factors passively, or whether private equity investments are a more efficient way to access these factor premiums. This would involve an analysis of transaction costs (and investor size) that is beyond the scope of this paper.

\section{$<$ Table $3>$}

The different factor models have different level of goodness of fit. For each sub-set of private equity funds, we select the model with the highest likelihood. We then obtain our best-fitted index for each type of private equity funds. Figure 4 - Panel A plots the cumulated log total return index, $g_{t}$, for venture capital (VC), buyout (BO) and real estate (RE) respectively.

We observe that VC had a sharp increase in returns in the late 1990s, peaked mid-2000 and then decreased sharply. VC returns remained flat then increased sharply from 2012. BO returns have different cycles. They were relatively flat up until 2003, before increasing sharply up until early 2007. They collapsed with the 2008 crisis but bounced back quickly, coincident with Quantitative Easing (QE) ${ }^{28}$

\footnotetext{
${ }^{28}$ Many buyout funds refinanced their investments from mid-2010 when QE started and could pay large dividends as a result. Also IPO activity resumed at about the same time and many LBO investments were exited that way. But again,
} 
RE returns increased steadily up until the crisis with a clear acceleration from 2003, then experienced a collapse but returns recovered from 2012. Remarkably, we note that real estate started to decline in the third quarter of 2007 , much ahead of available appraisal-based commercial property indexes. This is consistent with casual evidence that the U.S. real estate market started to decline from the third quarter of 2007.

The fact we obtain such marked and coherent cycles while only using factor returns and the cash flows of funds as classified Preqin suggests that the estimation recovers more than the levered market index or a combination of factors. It is remarkable that we get such diverse cycles across fund types while all the estimations used the same set of factors. These cycles are also consistent with conventional beliefs as reflected in industry reports and press coverage.

In addition, the imperfect co-movement across return indexes suggests that venture capital, real estate, and buyout fund cycles differ from one another. Hence, there are benefits to diversifying across private equity investment classes. More generally, the evidence suggests that, even conditional on differing exposures to systematic factors, private equity returns in different asset classes are influenced by other trends unrelated to publicly traded securities. ${ }^{29}$

Figure 4 - Panel B plots our (log) index of buyout funds and compare it to the cumulated (log) returns of the Vanguard S\&P 500 index fund and that of DFA value mutual fund (a passive low cost mutual fund with a long track record investing in value stocks). Consistent with the findings of Harris, Jenkinson, and Kaplan (2013), and Robinson and Sensoy (2011), and results in Table 3 buyout funds outperform the S\&P 500 index. Our above results show that part of this performance, however, is replicable using our estimated passive factor exposures. In addition, DFA value mutual fund returns exhibit a very similar pattern to those of the buyout index. Value stocks experienced high returns from 2003, which is when buyout funds also posted high returns and started to raise record amounts of capital. As buyout funds tend to invest in value companies, this finding has implications for benchmarking and asset allocation decisions. For example, a relatively small investors would have been apparently similarly well off with value stocks as with buyout funds.

\section{$<$ Figure $4>$}

our estimation method does not rely on observing an exit. The identification comes from observing higher NPV for funds that held more investments in their portfolio from mid-2010. This is what identifies the turning point.

${ }^{29} \mathrm{We}$ note also that our private equity indices are relatively insensitive to the assumed model for systematic risk (nontabulated). 


\subsection{Comparison to industry indexes}

One practical advantage of our cash flow-based index is that it seeks to attribute returns to the time period in which they occur. In practice, there are some industry indices with the same objective but they either use self-reported Net Asset Values (NAVs) or listed stocks of companies that are in the private equity industry.

NAVs are potentially subject to inertia - for example anchoring on prior appraisal values. The econometrics of appraisal-based indices have been well-studied for commercial real estate (cf. Geltner (1991)). Among other things, they have volatilities which under-estimate true volatilities and lag market values. In this section we examine the relationship of our cash-flow based index to industry indices.

In Table 4, we show the annualized mean, standard deviation, inter-quartile range and autocorrelation coefficient for some standard industry indices and for our cash flow-based indices ("CF index"). For the industry-standard NAV-based indices, we use those of Cambridge Associates. For the listed equity-based indices we use those of LPX. All the mean and volatility estimates in Table 4 are annualized.

\section{$<$ Table $4>$}

Table 4 shows that our cash flow-based indices are more volatile than the industry indices. The difference is particularly dramatic for real estate and buyout. For buyouts, the volatility of our cash flow-based return time-series is more than twice as high as that of Cambridge Associates (25\% compared to $11 \%$ ). But it is smaller than the volatility of the LPX buyout index, which is the one that has been used in recent capital requirement regulation (e.g. Solvency II). ${ }^{30}$

We estimate a volatility of $21 \%$ per annum for real estate, compared to $10 \%$ for Cambridge Associates. ${ }^{31}$ Interestingly, $21 \%$ is exactly the volatility of the FTSE listed real estate index based on returns of listed real estate funds (called REITS). This suggests that our estimated index may provide a more realistic estimate of real estate portfolio risk for investment managers.

\footnotetext{
${ }^{30}$ Europe's key insurance regulator, the Solvency II Committee, has been criticized for using LPX indices as a basis for value-at-risk parameters rather than less-volatile appraisal-based indices in their calculations of private equity capital requirements. Our estimates derived from private equity funds cash flows lie between these two and is generally closer to those of the LPX indices.

${ }^{31}$ The NCREIF index, a commonly used index, has a volatility of only $5 \%$. It is also appraisal-based.
} 
There is a smaller difference in volatilities for venture capital, at $30 \%$ for our index and $26 \%$ for the venture capital index produced by Cambridge Associates. Note that the latter is solely driven by a sharp spike in volatility in 1999.

These results indicate that existing private equity return time-series exhibit smoothing biases likely due to the appraisal process and the fact that valuations of illiquid assets may only partially adjust to market prices. In addition, we find that our private equity return time-series exhibit much less serial dependence, if any, in contrast to industry indices. ${ }^{32}$

\subsection{Test of the market segmentation hypothesis}

The cyclicality of private equity represents a challenge to private equity investors who are faced with the decision of how to time their investments, or how to maintain a continuous commitment to the asset class and manage expectations about short-term performance. This pattern is also difficult to explain in a standard economic framework. Kaplan and Strömberg (2009) introduce a novel theory of boom and bust cycles in private equity. They propose that funds exploit segmentation between the debt and equity markets. ${ }^{33}$ Kaplan and Strömberg (2009) extend the insights of the behavioral corporate finance literature to explain this correlation. In particular, Baker, Greenwood, and Wurgler (2003) present evidence that corporations choose financing channels based on the relative capital market demand for equity vs. debt. Kaplan and Strömberg (2009) argue that the ultimate source of the variation in relative demand for debt vs. equity is market sentiment, and they report suggestive evidence of this by charting a variable defined as the EBITDA/enterprise value minus the high yield spread. When this variable is high, private equity should be relatively profitable because the cost of debt financing is low compared to the return on assets.

Our cash flow-based buyout index allows us to empirically test the behavioral market segmentation hypothesis. In particular, we test whether private equity is profitable when the Kaplan-Stromberg asset-debt yield spread is higher. Table 5 reports the results of regressions in which our private equity cash flow index is the dependent variable and the independent variables include the assetdebt yield spread, the expected risk premium, the volume of buyout transactions (scaled by stock

\footnotetext{
${ }^{32}$ We also used Getmansky, Lo, and Makarov (2004) techniques to unsmooth appraisal-based return time-series. We find that the volatility of the buyout series goes up to $16 \%$, that of venture capital goes up to about $40 \%$ and that of real estate goes up to $16 \%$ (non-tabulated).

${ }^{33}$ Prior researchers have noted the connection between low interest rates and buyout fundraising (see Axelson et al. (2013), Ivashina and Kovner (2011), Demiroglu and James (2010)).
} 
market capitalization), the Baker-Wurgler sentiment index, and a set of macro-economic variables that capture credit conditions (the default spread, which is the difference in yields on AAA and BAA AAA rated debt) and the health of the economy (growth in industrial production, inflation, and the change in the VIX index).

\section{$<$ Table $5>$}

Our specification jointly tests the theory that market sentiment provides the opportunity for private equity managers to create value, and that the source of that value is the asset-debt yield spread. If market sentiment is a significant determinant of private equity returns we expect a positive sign on the sentiment index and a negative sign on the change in the VIX. In our specification the sign on the default spread may go either way since, by construction, it is negatively correlated to the assetdebt spread.

Results are shown in Table 5. We find that our index is significantly positively related to the assetdebt spread, consistent with the Kaplan-Strömberg hypothesis. It is negatively related to the change in VIX, and positively related to both transaction volume and the expected risk premium. These results are consistent with the hypothesis that private equity does well when the economy does well, and with the results in Haddad, Loualiche, and Plosser (2016).

One qualification of these findings is that we are measuring the contemporaneous effects of the asset-debt yield spread. The proposed channel by which this adds value is via the purchase of a higher yielding asset financed by issuing cheap debt. The fund cash flows we observe are deployment or realization of capital and are thus conditional on such a transaction occurring. Nevertheless, our index assumes that all firms in operation at a given date experience the same shocks. If we could separate transacting firms from firms that were not exploiting the spread, we may find a larger effect. 


\section{Conclusion}

Researchers and practitioners interested in understanding private equity investment have been limited by the structure and nature of the data. This has made it particularly difficult to evaluate its time-series characteristics. We present a methodology for extracting a latent performance measure from non-periodic cash flow information, and demonstrate how it may be further decomposed into passive and active components. We find that private equity returns are only partially spanned by investable passive indices. Our estimate suggests that private equity is, to a first approximation, a levered investment in small and mid-cap equities.

We estimate the private equity return for separate classes and show that their cycles are not highly correlated. This suggests that a diversified strategy across sub-asset classes of private equity may be beneficial. Our cash flow-based private equity indices also allow us to test current theories about the cyclical nature of private equity returns. In particular, we find evidence in favor of the Kaplan and Strömberg (2009)'s hypothesis that relative yields on corporate assets compared to high-yield debt explain the returns of private equity investments.

Our methodology and results also have potential regulatory implications. Volatility measures for private equity based on our cash flow-based return series are at least as volatile as standard aggregate equity market indices. In contrast, estimates of private equity volatility constructed from appraisal-based indices are much lower. The Solvency II Committee, the European Union's flagship project to harmonize European insurance supervision and set capital requirements (similar to Basel II), has chosen to use a publicly traded proxy for private equity returns. Our results suggest the volatility estimates derived from such an index are close to the volatility of true private equity returns. Investors and regulators all benefit from more accurate estimates of returns and risk from illiquid private equity. 


\section{References}

Ang, Andrew, and Jun Liu, 2004, How to Discount Cashflows with Time-Varying Expected Returns, Journal of Finance 59, 2745-2783.

Baker, Kenneth, and Dan Trietsch, 2013, Principles of Sequencing and Scheduling (John Wiley \& Sons, Inc.).

Baker, Malcolm, Robin Greenwood, and Jeffrey Wurgler, 2003, The maturity of debt issues and predictable variation in bond returns, Journal of Financial Economics 70, 261.

Barakat, Richard, 1976, Sums of independent lognormally distributed random variables, Journal of the Optical Society of America 66, 211-216.

Barber, Brad M, and Ayako Yasuda, 2017, Interim Fund Performance and Fundraising in Private Equity, Journal of Financial Economics 124, 172-194.

Brennan, Michael J, 1997, The Term Structure of Discount Rates, FM: The Journal of the Financial Management Association 26, 81-90.

Brown, Gregory W, Oleg Gredil, and Steven N Kaplan, 2015, Do Private Equity Funds Game Returns?, Working paper.

Choi, Wonho Wilson, Andrew Metrick, and Ayako Yasuda, 2012, A Model of Private Equity Fund Compensation, The Global Macroeconomy and Finance.

Cochrane, John H, 2005, The risk and return of venture capital, Journal of Financial Economics 75, $3-52$.

Driessen, Joost, Tse-Chun Lin, and Ludovic Phalippou, 2012, A New Method to Estimate Risk and Return of Nontraded Assets from Cash Flows: The Case of Private Equity Funds, Journal of Financial \& Quantitative Analysis 47, 511-535.

Fama, Eugene F, and Kenneth R French, 1993, Common risk factors in the returns on stocks and bonds, Journal of Financial Economics 33, 3-56.

Fama, Eugene F, and Kenneth R French, 2015, A five-factor asset pricing model, Journal of Financial Economics 116, 1-22.

Fenton, Lawrence, 1960, The sum of log-normal probability distributions in scatter transmission systems, IRE Transactions on Communication Systems 8, 57-67.

Franzoni, Francesco, Eric Nowak, and Ludovic Phalippou, 2012, Private Equity Performance and Liquidity Risk, Journal of Finance 67, 2341-2373.

Frazzini, Andrea, and Lasse Heje Pedersen, 2014, Betting Against Beta, Journal of Financial Economics 111, 1-25.

Geltner, David, 1991, Smoothing in Appraisal-Based Returns, Journal of Real Estate Finance and Economics 4, 327-345.

Getmansky, Mila, Andrew W Lo, and Igor Makarov, 2004, An econometric model of serial correlation and illiquidity in hedge fund returns, Journal of Financial Economics 74, 529-609.

Goetzmann, William N, Jonathan E Ingersoll, and Stephen A Ross, 2003, High-Water Marks and Hedge Fund Management Contracts, Journal of Finance 58, 1685-1718. 
Haddad, Valentin, Erik Loualiche, and Matthew C Plosser, 2016, Buyout Activity: the Impact of Aggregate Discount Rates, Journal of Finance, forthcoming.

Harris, Robert S, Tim Jenkinson, and Steven N Kaplan, 2013, Private Equity Performance: What Do We Know?, Journal of Finance, forthcoming.

Harris, Robert S, Tim Jenkinson, and Steven N Kaplan, 2015, How Do Private Equity investments Perform Compared to Public Equity?, Journal of Investment Management, forthcoming.

Jagannathan, Ravi, and Morten Sorensen, 2015, The Public Market Equivalent and Private Equity Performance, Financial Analysts Journal 71, 43-50.

Kaplan, Steven N, and Per Johan Strömberg, 2009, Leveraged Buyouts and Private Equity, Journal of Economic Perspectives 23, 121-146.

Korteweg, Arthur, and Stefan Nagel, 2015, Risk-Adjusting the Returns to Venture Capital, Journal of Finance, forthcoming.

Korteweg, Arthur, and Morten Sorensen, 2010, Risk and Return Characteristics of Venture CapitalBacked Entrepreneurial Companies, Review of Financial Studies 23, 3738-3772.

Ljungqvist, Alexander, and Matthew Richardson, 2003, The Investment Behavior of Private Equity Fund Managers, Unpublished working paper. NYU.

Metrick, Andrew, and Ayako Yasuda, 2010, The Economics of Private Equity Funds, Review of Financial Studies 23, 2303-2341.

Nadauld, Taylor, Berk Sensoy, Keith Vorkink, and Michael Weisbach, 2015, The Liquidity Cost of Private Equity Investments: Evidence from Secondary Market Transactions, Working Paper.

Pástor, Luboš, and Robert F Stambaugh, 2003, Liquidity Risk and Expected Stock Returns, Journal of Political Economy 111, 642-685.

Phalippou, Ludovic, 2013, Performance of Buyout Funds Revisited?, Review of Finance, Forthcoming.

Robinson, David T, and Berk A Sensoy, 2013, Cyclicality, Performance Measurement, and Cash Flow Liquidity in Private Equity, NBER Working Paper No. 17428.

Ross, Stephen A, and Randall C Zisler, 1991, Risk and Return in Real Estate, Journal of Real Estate Finance \& Economics 4, 175-190.

Sorensen, Morten, Neng Wang, and Jinqiang Yang, 2014, Valuing Private Equity, Review of Financial Studies 27, 1977-2021.

Stafford, Erik, 2016, Replicating Private Equity with Value Investing, Homemade Leverage, and Hold-to-Maturity Accounting. Harvard Business School Working Paper. 


\section{Table 1: Monte Carlo Simulations when the error structure is as specified in our model}

We generate a set of cash flows for 500 funds over 80 quarters. Each case is simulated 100 times. In Panel A, we report the mean and volatility of the estimated time series of returns and the correlation and Mean Squared Error between the estimated and true time-series of returns. In Panel B estimated Alpha and Beta quartiles are shown. There are six cases. The simple case is when investments are held for two quarters on average and the standard deviation of the PVR across funds is $\sigma_{h}^{2}=1 \%$ (referred to as idiosyncratic volatility). Each of the following cases changes one parameter at a time and keeps the previous changes made. Case 2 increases average holding period to 3.5 years. Case 3 increases idiosyncratic volatility to $10 \%$. Case 4 increases the number of investments per fund from 5 to 20 . Case 5 shows results when the true error term is uniformly distributed instead of log normally distributed. Case 6 has, in addition to all of the previous 'handicaps', the wrong priors (prior on alpha is zero and prior on beta is one).

Panel A: Recovering the full time-series of returns

\begin{tabular}{lcccc}
\hline & Mean & Volatility & Correlation & MSE (*100) \\
\cline { 2 - 5 } Truth & 0.16 & 0.32 & $100.0 \%$ & 0.00 \\
1. Simple case & 0.16 & 0.32 & $98.7 \%$ & 0.06 \\
2. Increase holding period & 0.16 & 0.32 & $97.6 \%$ & 0.12 \\
3. Increase idiosyncratic volatility & 0.17 & 0.32 & $96.0 \%$ & 0.20 \\
4. More investments per fund & 0.17 & 0.32 & $95.3 \%$ & 0.21 \\
5. Error is not log-normally distributed & 0.17 & 0.32 & $95.0 \%$ & 0.24 \\
6. Wrong priors & 0.16 & 0.30 & $94.5 \%$ & 0.26 \\
\hline
\end{tabular}

Panel B: Recovering model parameters

\section{Truth}

1. Simple case

2. Increase holding period

3. Increase idiosyncratic volatility

4. More investments per fund

5. Error is not log-normally distributed

5. Wrong priors

\begin{tabular}{|c|c|c|c|c|c|c|}
\hline \multirow[b]{2}{*}{ Percentiles } & \multicolumn{3}{|c|}{ Alpha } & \multicolumn{3}{|c|}{ Beta } \\
\hline & $25^{\text {th }}$ & $50^{\text {th }}$ & $75^{\text {th }}$ & $25^{\text {th }}$ & $50^{\text {th }}$ & $75^{\text {th }}$ \\
\hline & \multicolumn{3}{|c|}{0.04} & \multicolumn{3}{|c|}{1.50} \\
\hline & 0.02 & 0.04 & 0.05 & 1.47 & 1.50 & 1.53 \\
\hline & 0.02 & 0.04 & 0.05 & 1.47 & 1.50 & 1.53 \\
\hline & 0.03 & 0.05 & 0.06 & 1.45 & 1.50 & 1.55 \\
\hline & 0.03 & 0.05 & 0.06 & 1.45 & 1.50 & 1.55 \\
\hline ed & 0.03 & 0.05 & 0.06 & 1.45 & 1.50 & 1.55 \\
\hline & 0.04 & 0.06 & 0.07 & 1.23 & 1.27 & 1.31 \\
\hline
\end{tabular}


Table 2: Descriptive Statistics - Preqin versus Burgiss datasets

This table shows the median and average fund PMEs, which compare private equity returns to equivalent-timed investments in the S\&P 500 index. Statistics are displayed by vintage years (from 1994 to 2008). Average is weighted using the capital committed to the funds as weights. Statistics derived from the Burgiss dataset are as reported by Harris, Jenkinson, and Kaplan (2015). Preqin is our working dataset. Panel A focuses on venture capital funds while Panel B focuses on buyout funds. Only funds with a US-focus are included in this table.

Panel A: Venture Capital fund PMEs

\begin{tabular}{|c|c|c|c|c|c|c|}
\hline & \multicolumn{3}{|c|}{ Burgiss } & \multicolumn{3}{|c|}{ Preqin } \\
\hline & Funds & Median & Average & Funds & Median & Average \\
\hline 1994 & 23 & 1.40 & 3.42 & 11 & 1.41 & 3.92 \\
\hline 1995 & 28 & 1.49 & 3.14 & 16 & 1.62 & 2.76 \\
\hline 1996 & 23 & 2.16 & 4.34 & 15 & 1.33 & 2.17 \\
\hline 1997 & 42 & 1.43 & 2.68 & 21 & 0.96 & 1.66 \\
\hline 1998 & 58 & 0.99 & 1.74 & 30 & 1.00 & 1.51 \\
\hline 1999 & 88 & 0.67 & 0.89 & 37 & 0.60 & 0.71 \\
\hline 2000 & 109 & 0.66 & 0.78 & 71 & 0.68 & 0.80 \\
\hline 2001 & 58 & 0.83 & 0.91 & 43 & 0.79 & 1.04 \\
\hline 2002 & 21 & 0.76 & 0.79 & 24 & 0.63 & 0.82 \\
\hline 2003 & 30 & 0.81 & 1.09 & 13 & 0.99 & 0.86 \\
\hline 2004 & 49 & 0.75 & 1.23 & 29 & 0.72 & 0.92 \\
\hline 2005 & 59 & 0.80 & 0.98 & 27 & 0.94 & 1.24 \\
\hline 2006 & 70 & 0.80 & 0.95 & 41 & 0.80 & 0.86 \\
\hline 2007 & 84 & 0.93 & 1.08 & 42 & 1.07 & 1.02 \\
\hline 2008 & 58 & 0.85 & 1.05 & 33 & 0.95 & 0.99 \\
\hline Average & & 1.02 & 1.67 & & 0.97 & 1.42 \\
\hline All funds & 800 & & & 453 & & \\
\hline
\end{tabular}

Panel B: Buyout fund PMEs

\begin{tabular}{|c|c|c|c|c|c|c|}
\hline & \multicolumn{3}{|c|}{ Burgiss } & \multicolumn{3}{|c|}{ Preqin } \\
\hline & Funds & Median & Average & Funds & Median & Average \\
\hline 1994 & 20 & 1.09 & 1.46 & 18 & 1.09 & 1.21 \\
\hline 1995 & 23 & 1.01 & 1.17 & 11 & 0.84 & 1.05 \\
\hline 1996 & 18 & 1.13 & 1.05 & 13 & 1.13 & 1.17 \\
\hline 1997 & 31 & 1.03 & 1.27 & 21 & 1.43 & 1.45 \\
\hline 1998 & 46 & 1.40 & 1.31 & 31 & 1.17 & 1.15 \\
\hline 1999 & 34 & 1.21 & 1.13 & 24 & 1.40 & 1.23 \\
\hline 2000 & 60 & 1.38 & 1.48 & 30 & 1.52 & 1.60 \\
\hline 2001 & 31 & 1.49 & 1.48 & 18 & 1.40 & 1.51 \\
\hline 2002 & 23 & 1.34 & 1.51 & 17 & 1.29 & 1.51 \\
\hline 2003 & 23 & 1.40 & 1.55 & 12 & 1.48 & 1.71 \\
\hline 2004 & 50 & 1.29 & 1.45 & 30 & 1.35 & 1.41 \\
\hline 2005 & 66 & 1.12 & 1.26 & 32 & 1.06 & 1.36 \\
\hline 2006 & 80 & 1.03 & 1.02 & 44 & 1.09 & 1.03 \\
\hline 2007 & 86 & 0.97 & 0.99 & 43 & 1.02 & 1.05 \\
\hline 2008 & 64 & 0.96 & 1.03 & 39 & 0.99 & 1.02 \\
\hline Average & & 1.19 & 1.28 & & 1.21 & 1.29 \\
\hline All funds & 655 & & & 423 & & \\
\hline
\end{tabular}




\section{Table 3: Private Equity Factor Exposures}

This table shows the estimated risk loadings, and abnormal returns $\alpha$ using eight different asset pricing factor models. Panel A includes all US private equity funds (except fund-of-funds) in the Preqin dataset ( $\mathrm{N}=1089$ ); Panel B includes all US venture capital funds (includes funds classified as balanced and growth); and Panel C includes all US buyout funds. Funds are raised between 1994 and 2008, and cash flows start in the first quarter of 1994 and ends in the second quarter of 2015. Alpha is annualized and defined as the constant that makes the average value-weighted PME equal to one, given the estimated risk loadings. Underneath each coefficient, in italics, we report the posterior standard deviation of the estimated parameters. The "Classic" factor models that we use are: the CAPM, the three factor model of Fama and French (1993), and the four factor model is that of Pástor and Stambaugh (2003). The "Amended Equally-weighted market portfolio" model replaces the CRSP value-weighted index as a measure of market returns by i) the CRSP equally-weighted index (Panel A); or ii) Equally-weighted Nasdaq index (Panel B); or iii) Equally-weighted AMEX/NYSE index (Panel C). The "Amended Traded Factors" models use the following respective four traded factors: Vanguard S\&P 500 minus the risk free rate, DFA microcap mutual fund minus Vanguard S\&P 500, DFA value mutual fund minus Vanguard S\&P 500, and T.Rowe High Yield minus Vanguard S\&P 500. The "New Fama-French 5 factors" includes "profitability" and "investment" as defined on Kenneth French's website. Priors for the factor loadings are given in Appendix Table 1.

Panel A: All private equity funds

\begin{tabular}{|c|c|c|c|c|c|c|c|}
\hline Models & $\beta_{\text {market }}$ & $\beta_{\text {size }}$ & $\beta_{\text {value }}$ & $\beta_{\text {illiquidity }}$ & & $\alpha$ & Likelihood \\
\hline \multirow[t]{2}{*}{ 1 factor (CAPM) } & $1.43^{\mathrm{a}}$ & & & & & $0.02^{\mathrm{a}}$ & -68 \\
\hline & 0.21 & & & & & 0.00 & \\
\hline \multirow[t]{2}{*}{3 factors $(\mathrm{FF})$} & $1.51^{\mathrm{a}}$ & $0.81^{\mathrm{c}}$ & -0.07 & & & $0.01^{\mathrm{c}}$ & -63 \\
\hline & 0.26 & 0.45 & 0.28 & & & 0.01 & \\
\hline \multirow[t]{2}{*}{4 factors (PS) } & $1.54^{\mathrm{a}}$ & $0.82^{\mathrm{c}}$ & -0.12 & 0.51 & & $-0.01^{\mathrm{c}}$ & -64 \\
\hline & 0.28 & 0.46 & 0.26 & 0.33 & & 0.01 & \\
\hline \multirow[t]{2}{*}{1 factor $(\mathrm{EW})$} & $1.40^{\mathrm{a}}$ & & & & & -0.01 & -72 \\
\hline & 0.20 & & & & & 0.01 & \\
\hline \multirow[t]{2}{*}{ Traded 1 factor } & $1.63^{\mathrm{a}}$ & & & & & $-0.02^{\mathrm{a}}$ & -70 \\
\hline & 0.28 & & & & & 0.01 & \\
\hline \multirow[t]{2}{*}{ Traded 3 factors } & $1.57^{\mathrm{a}}$ & $0.83^{\mathrm{b}}$ & -0.12 & & & $-0.02^{\mathrm{a}}$ & -65 \\
\hline & 0.26 & 0.40 & 0.26 & & & 0.01 & \\
\hline \multirow[t]{2}{*}{ Traded 4 factors } & $1.81^{\mathrm{a}}$ & $0.81^{\mathrm{b}}$ & -0.12 & 0.44 & & $-0.05^{\mathrm{a}}$ & -65 \\
\hline & 0.36 & 0.40 & 0.27 & 0.43 & & 0.01 & \\
\hline \multicolumn{8}{|c|}{ New Fama-French 5 factors model } \\
\hline & $\beta_{\text {market }}$ & $\beta_{\text {size }}$ & $\beta_{\text {value }}$ & $\beta_{\text {profitability }}$ & $\beta_{\text {investment }}$ & $\alpha$ & Likelihood \\
\hline & $1.88^{\mathrm{a}}$ & $1.04^{\mathrm{b}}$ & -0.19 & 0.49 & 0.16 & $-0.02^{\mathrm{b}}$ & -62 \\
\hline & 0.36 & 0.46 & 0.20 & 0.37 & 0.42 & 0.01 & \\
\hline
\end{tabular}


Panel B: Venture Capital funds

\begin{tabular}{|c|c|c|c|c|c|c|c|}
\hline Models & $\beta_{\text {market }}$ & $\beta_{\text {size }}$ & $\beta_{\text {value }}$ & $\beta_{\text {illiquidity }}$ & & $\alpha$ & Likelihood \\
\hline \multirow{2}{*}{ 1factor (CAPM) } & $1.80^{\mathrm{a}}$ & & & & & 0.00 & -115 \\
\hline & 0.30 & & & & & 0.01 & \\
\hline \multirow[t]{2}{*}{3 factors $(\mathrm{FF})$} & $1.72^{\mathrm{a}}$ & $0.81^{\mathrm{b}}$ & -0.61 & & & 0.01 & -102 \\
\hline & 0.31 & 0.39 & 0.41 & & & 0.01 & \\
\hline \multirow[t]{2}{*}{4 factors (PS) } & $1.73^{\mathrm{a}}$ & $0.89^{b}$ & -0.64 & 0.49 & & $-0.03^{\mathrm{a}}$ & -105 \\
\hline & 0.30 & 0.41 & 0.40 & 0.33 & & 0.01 & \\
\hline \multirow[t]{2}{*}{1 factor $(\mathrm{EW})$} & $1.46^{\mathrm{a}}$ & & & & & $-0.03^{\mathrm{a}}$ & -123 \\
\hline & 0.17 & & & & & 0.01 & \\
\hline \multirow[t]{2}{*}{ Traded 1 factor } & $1.82^{\mathrm{a}}$ & & & & & $-0.04^{\mathrm{a}}$ & -109 \\
\hline & 0.31 & & & & & 0.01 & \\
\hline \multirow[t]{2}{*}{ Traded 3 factors } & $1.85^{\mathrm{a}}$ & $1.03^{\mathrm{b}}$ & $-0.82^{b}$ & & & $-0.04^{\mathrm{a}}$ & -102 \\
\hline & 0.33 & 0.43 & 0.37 & & & 0.01 & \\
\hline \multirow[t]{2}{*}{ Traded 4 factors } & $2.09^{\mathrm{a}}$ & $0.91^{\mathrm{b}}$ & $-0.90^{b}$ & 0.60 & & $-0.05^{\mathrm{a}}$ & -101 \\
\hline & 0.41 & 0.41 & 0.37 & 0.42 & & 0.01 & \\
\hline \multicolumn{8}{|c|}{ New Fama-French 5 factors model } \\
\hline & $\beta_{\text {market }}$ & $\beta_{\text {size }}$ & $\beta_{\text {value }}$ & $\beta_{\text {profitability }}$ & $\beta_{\text {investment }}$ & $\alpha$ & Likelihood \\
\hline & $1.99^{\mathrm{a}}$ & $0.93^{\mathrm{b}}$ & $-0.80^{\mathrm{b}}$ & 0.70 & 0.43 & $-0.05^{\mathrm{a}}$ & -109 \\
\hline & 0.39 & 0.44 & 0.41 & 0.49 & 0.53 & 0.01 & \\
\hline
\end{tabular}

Panel C: Buyout funds

\begin{tabular}{|c|c|c|c|c|c|c|c|}
\hline Models & $\beta_{\text {market }}$ & $\beta_{\text {size }}$ & $\beta_{\text {value }}$ & $\beta_{\text {illiquidity }}$ & & $\alpha$ & Likelihood \\
\hline \multirow[t]{2}{*}{ 1factor (CAPM) } & $1.25^{\mathrm{a}}$ & & & & & $0.04^{\mathrm{a}}$ & 120 \\
\hline & 0.25 & & & & & 0.01 & \\
\hline \multirow[t]{2}{*}{3 factors $(\mathrm{FF})$} & $1.22^{\mathrm{a}}$ & 0.47 & $0.60^{\mathrm{c}}$ & & & $0.01^{\mathrm{b}}$ & 119 \\
\hline & 0.27 & 0.47 & 0.33 & & & 0.01 & \\
\hline \multirow[t]{2}{*}{4 factors (PS) } & $1.32^{\mathrm{a}}$ & 0.63 & $0.66^{\mathrm{c}}$ & $0.56^{\mathrm{b}}$ & & $-0.03^{\mathrm{a}}$ & 118 \\
\hline & 0.29 & 0.48 & 0.37 & 0.26 & & 0.01 & \\
\hline \multirow[t]{2}{*}{1 factor $(\mathrm{EW})$} & $1.18^{\mathrm{a}}$ & & & & & $0.02^{\mathrm{a}}$ & 116 \\
\hline & 0.24 & & & & & 0.01 & \\
\hline \multirow[t]{2}{*}{ Traded 1 factor } & $1.22^{\mathrm{a}}$ & & & & & $0.02^{\mathrm{a}}$ & 116 \\
\hline & 0.26 & & & & & 0.01 & \\
\hline \multirow[t]{2}{*}{ Traded 3 factors } & $1.31^{\mathrm{a}}$ & 0.33 & $0.70^{\mathrm{c}}$ & & & $-0.02^{\mathrm{b}}$ & 115 \\
\hline & 0.29 & 0.45 & 0.40 & & & 0.01 & \\
\hline \multirow[t]{2}{*}{ Traded 4 factors } & $1.77^{\mathrm{a}}$ & 0.02 & $0.48^{\mathrm{c}}$ & $1.08^{\mathrm{b}}$ & & $-0.04^{\mathrm{a}}$ & 118 \\
\hline & 0.41 & 0.31 & 0.29 & 0.52 & & 0.01 & \\
\hline \multicolumn{8}{|c|}{ New Fama-French 5 factors model } \\
\hline & $\beta_{\text {market }}$ & $\beta_{\text {size }}$ & $\beta_{\text {value }}$ & $\beta_{\text {profitability }}$ & $\beta_{\text {investment }}$ & $\alpha$ & Likelihood \\
\hline & $1.60^{\mathrm{a}}$ & 0.44 & $0.67^{\mathrm{c}}$ & $1.06^{\mathrm{b}}$ & 0.25 & $-0.06^{\mathrm{a}}$ & 116 \\
\hline & 0.34 & 0.48 & 0.41 & 0.52 & 0.50 & 0.01 & \\
\hline
\end{tabular}




\section{Table 4: Comparison of Private Equity Index with Industry Indices}

Columns 2 to 6 show the following descriptive statistics for each index return: the annualized mean, volatility, $25^{\text {th }}$ and $75^{\text {th }}$ percentiles; and the autocorrelation coefficient (computed at quarterly frequency). Three indices are shown for each of four types of private equity funds: buyout, venture capital, real estate and all private equity. The three indices are our index, the Cambridge Associates index, and an index based on publicly listed companies. Data are from Q1-1995 to Q4-2014.

\begin{tabular}{ccccc} 
Mean & Volatility & \multicolumn{2}{c}{ Percentiles } & Autocorrelation \\
& & $25^{\text {th }}$ & $75^{\text {th }}$ & \\
\hline & & & & \\
0.17 & 0.26 & -0.21 & 0.52 & 0.09 \\
0.15 & 0.11 & 0.02 & 0.28 & 0.40 \\
0.14 & 0.29 & -0.04 & 0.36 & 0.19 \\
& & & & \\
0.17 & 0.31 & -0.15 & 0.53 & 0.14 \\
0.18 & 0.26 & 0.00 & 0.26 & 0.60 \\
0.11 & 0.37 & -0.37 & 0.45 & 0.12 \\
& & & & \\
0.13 & 0.21 & -0.08 & 0.42 & 0.11 \\
0.11 & 0.10 & 0.06 & 0.17 & 0.64 \\
0.13 & 0.21 & -0.09 & 0.38 & 0.14 \\
\hline
\end{tabular}




\section{Table 5: Private Equity Returns over the Business Cycle}

This Table shows how our cash flow-based buyout return index relates to macroeconomic variables. We compute $t$-statistics using Newey-West (1987) standard errors with four lags, which are shown underneath each coefficient in italics. Time period is from the first quarter of 1996 to the last quarter of 2014. The risk repmium and scaled volume is from Haddad, Loualiche, and Plosser (2016) and is only available until Q4-2011.

\begin{tabular}{|c|c|c|c|c|c|c|c|c|}
\hline \multirow[t]{2}{*}{ Constant } & 0.03 & 0.03 & -0.01 & -0.01 & -0.04 & -0.13 & -0.12 & -0.14 \\
\hline & 2.28 & 2.01 & -0.15 & -0.18 & -0.59 & -1.40 & -1.57 & -1.90 \\
\hline \multirow[t]{2}{*}{ Ebitda/EV - High yield spread } & 0.02 & 0.02 & 0.02 & 0.02 & 0.02 & 0.02 & 0.03 & 0.03 \\
\hline & 2.62 & 2.54 & 2.20 & 2.19 & 2.03 & 1.68 & 2.86 & 3.01 \\
\hline \multirow[t]{2}{*}{ Change in VIX index } & & 0.07 & 0.07 & 0.07 & 0.07 & 0.07 & 0.08 & 0.08 \\
\hline & & 1.53 & 1.65 & 1.67 & 1.60 & 1.85 & 1.71 & 1.82 \\
\hline \multirow[t]{2}{*}{ Default spread (BAA-AAA) } & & & 3.59 & 3.78 & 6.27 & 12.92 & 12.89 & 12.34 \\
\hline & & & 0.80 & 0.72 & 0.98 & 1.69 & 2.17 & 2.09 \\
\hline \multirow[t]{2}{*}{ Inflation } & & & & 0.33 & 0.37 & 0.20 & 0.71 & 0.78 \\
\hline & & & & 0.18 & 0.21 & 0.12 & 0.45 & 0.51 \\
\hline \multirow[t]{2}{*}{ Sentiment index } & & & & & 0.03 & 0.04 & 0.05 & 0.05 \\
\hline & & & & & 0.91 & 1.34 & 1.73 & 1.74 \\
\hline \multirow[t]{2}{*}{ Industrial production growth } & & & & & & 3.42 & 1.78 & 1.55 \\
\hline & & & & & & 1.73 & 0.82 & 0.70 \\
\hline \multirow[t]{2}{*}{ Risk premium } & & & & & & & 0.01 & 0.01 \\
\hline & & & & & & & 2.19 & 2.10 \\
\hline \multirow[t]{2}{*}{ Scaled volume } & & & & & & & & 0.00 \\
\hline & & & & & & & & 0.71 \\
\hline Adjusted R-squared & 0.10 & 0.13 & 0.14 & 0.14 & 0.15 & 0.22 & 0.37 & 0.37 \\
\hline Number of observations & 76 & 76 & 76 & 76 & 76 & 76 & 64 & 64 \\
\hline
\end{tabular}




\section{Figure 1. Monte Carlo Simulations with Listed Stocks as the Underlying Investments}

We generate a set of cash flows for 500 funds over 40 quarters. The simulation setup is described in details in the text. Each case is simulated 100 times. Each investment is matched to one of the 3,120 stocks with ten years of valid monthly data in CRSP (Q1-2001 to Q4-2010) and earns the same return as the matched stock during its holding period. The true return at time $t$ is the average return across the 3,120 stocks at time $t$, which is close (by construction) to the CRSP Equally Weighted stock index. The left panel compares the time-series of estimated returns (blue dashed line) and true returns (black solid line). The right panel shows the cumulative log return of these two return series as well as that of the CRSP Value Weighted index (dash-dotted red), and CRSP Equally Weighted index (astered green).
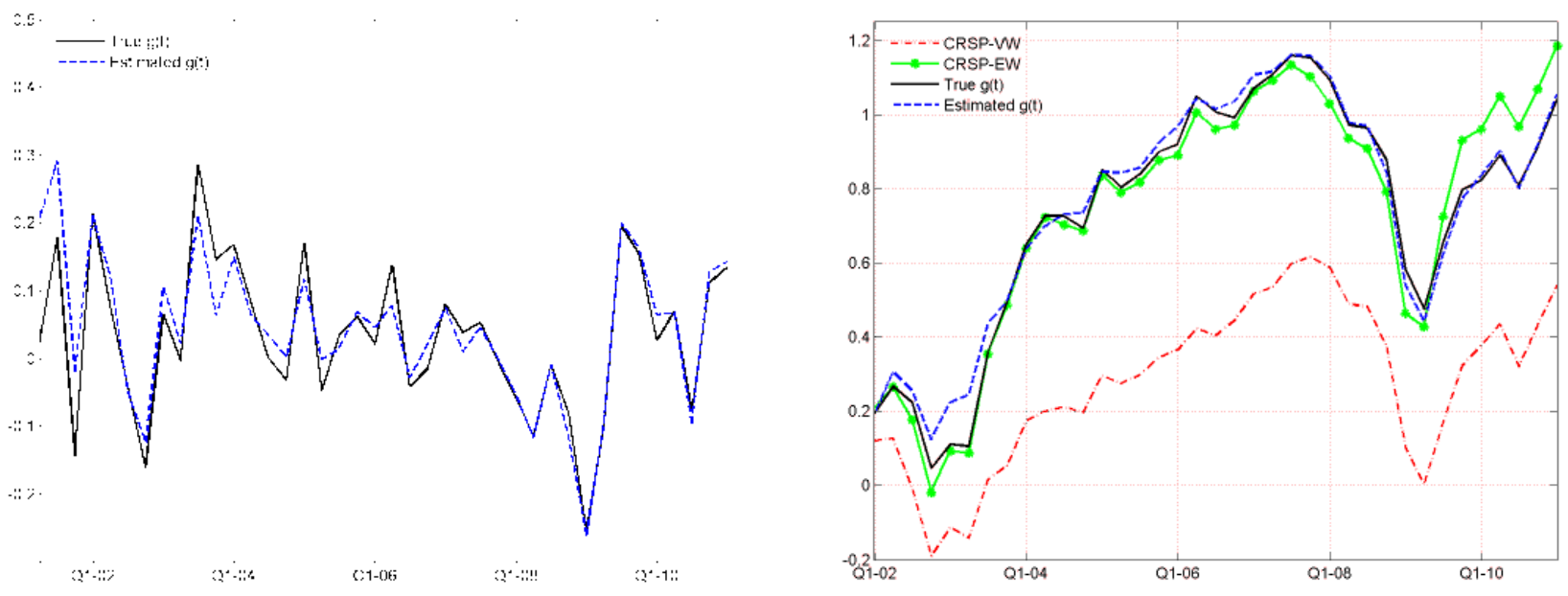


\section{Figure 2: Estimation Precision With Quarterly Return Shocks}

Average correlation obtained across simulations, as a function of the volatility (annualized) of the shock added each quarter to each investment return (referred to as idiosyncratic volatility). This quarterly error term is not modelled by the econometrician; instead the error term in the econometrics model is on the Net Present Value of funds. By default, the true time-series of returns are generated with a one factor model with a true beta of 1.5 , alpha of $4 \%$ p.a., plus a mean zero PE-specific return with $20 \%$ annual volatility plus idiosyncratic volatility. There is no autocorrelation is residuals and no fee structure applied to the cash flows; average holding period (duration) is 3.5 years, and the prior on beta is correct. The sample contains 600 funds that make 20 investments each. Panel A shows results with different annual volatility for the PE-specific return. Panel B shows results with different assumptions for the true beta level. Panel C shows results with different priors on beta; prior is lower than the true beta by a either $0.25,0.50$ or 0.75 . Panel $\mathrm{D}$ shows results with different number of funds in each economy. Panel E shows results with different holding periods.

Panel A: Using different levels of PE specific volatility

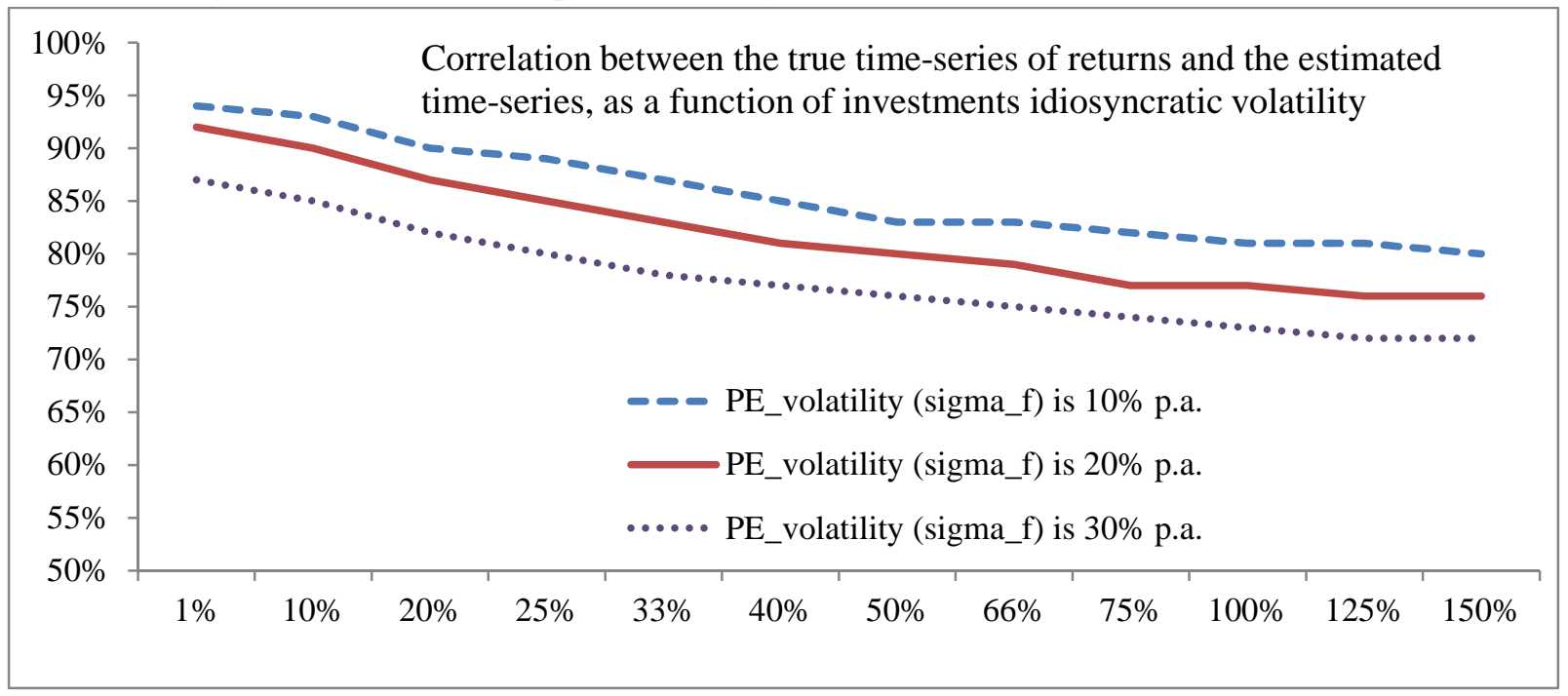


Panel B: Using different levels of Beta

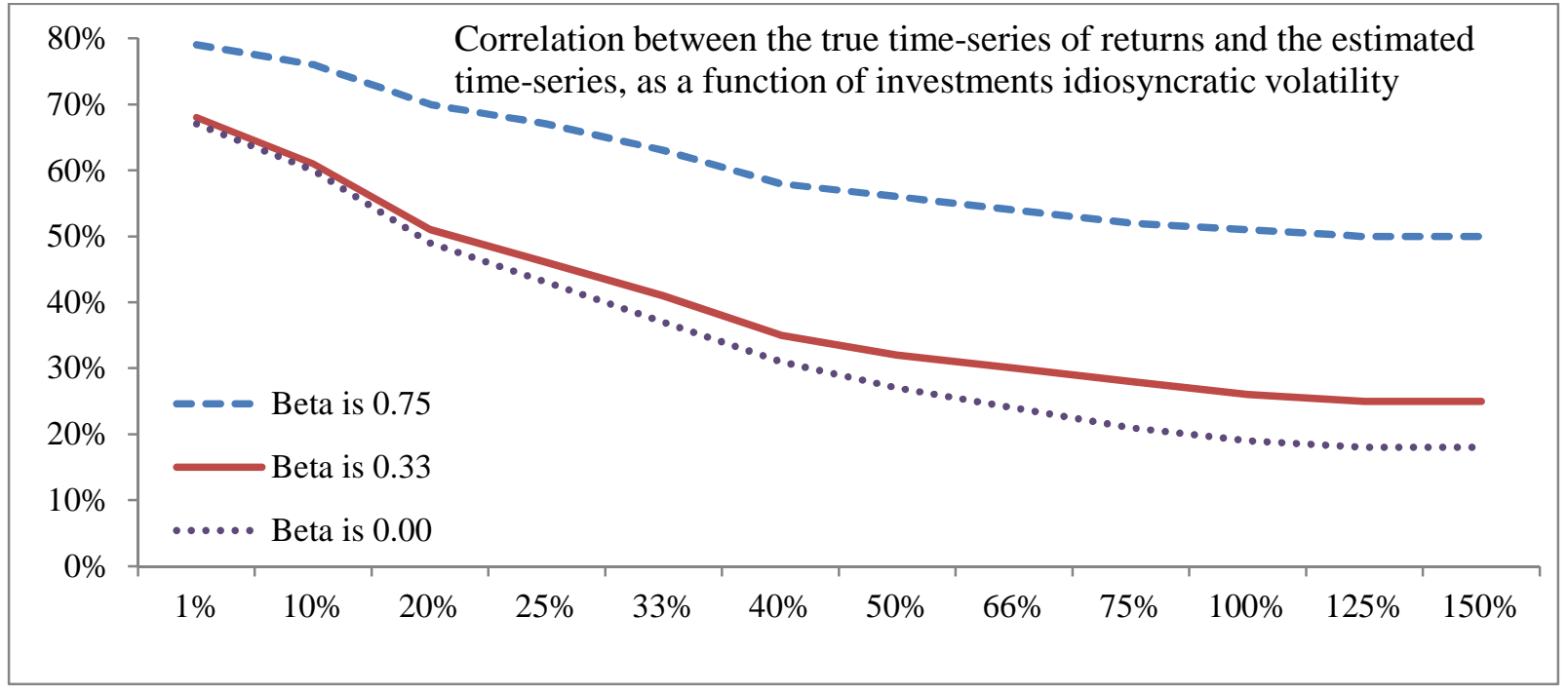

Panel C: Using different priors for Beta

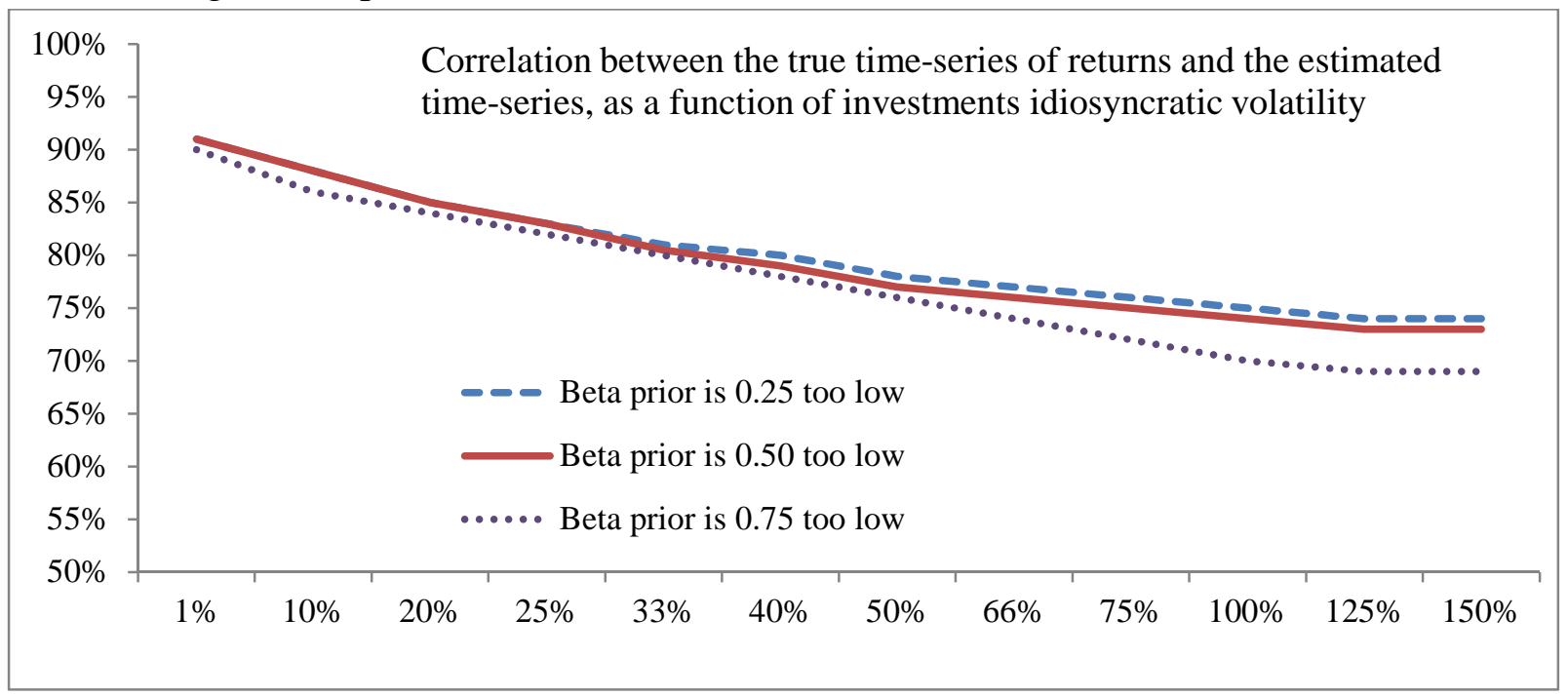


Panel D: Using different sample size

\begin{tabular}{|r|r||l}
$100 \%$ \\
$95 \%$ \\
$90 \%$ \\
$85 \%$ \\
$80 \%$ \\
$75 \%$ \\
$70 \%$ \\
$65 \%$ \\
$60 \%$ \\
$55 \%$ \\
$50 \%$
\end{tabular}

Panel E: Using different holding periods

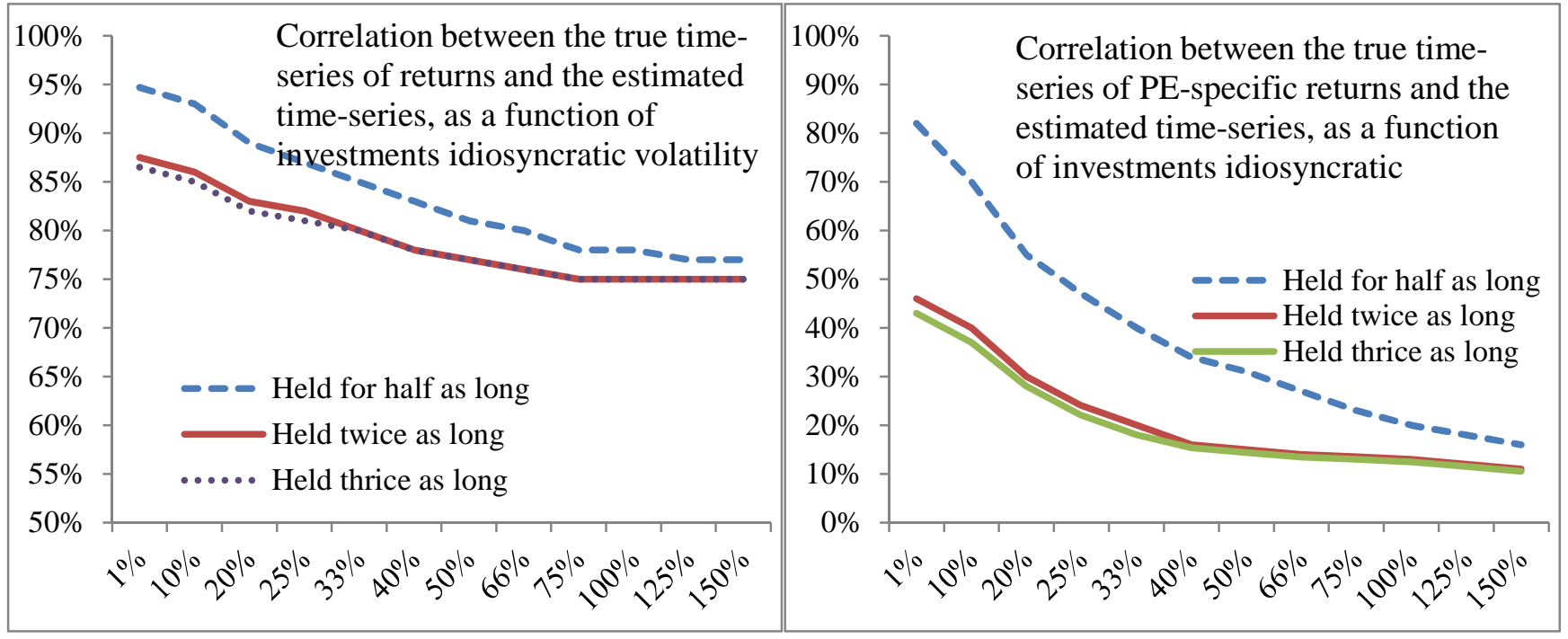




\section{Figure 3: The Impact of Un-modelled Fee Structure on Estimation Precision}

Average correlation obtained across simulations, as a function of the volatility (annualized) of the shock added each quarter to each investment return (referred to as idiosyncratic volatility). This quarterly error term is not modelled by the econometrician; instead the error term in the econometrics model is on the Net Present Value of funds. Returns are generated with a one factor model with a true beta of 1.5 , alpha of $4 \%$ p.a., plus a mean zero PE-specific return with $20 \%$ annual volatility plus idiosyncratic volatility. There is no autocorrelation is residuals; average holding period (duration) is 3.5 years, and the prior on beta is correct. The sample contains 600 funds that make 20 investments each. Panel A shows results with a standard fee structure, whereby carried interest is paid when investments are exited and management fees are charged on capital committed (hence generate a so-called J-curve). Panel B shows results with carried interest modelled as a continuous latent call option; the value of the investment each quarter is reduced by the change in the value of this option.

Panel A: Fee structure is modelled as a European-style waterfall

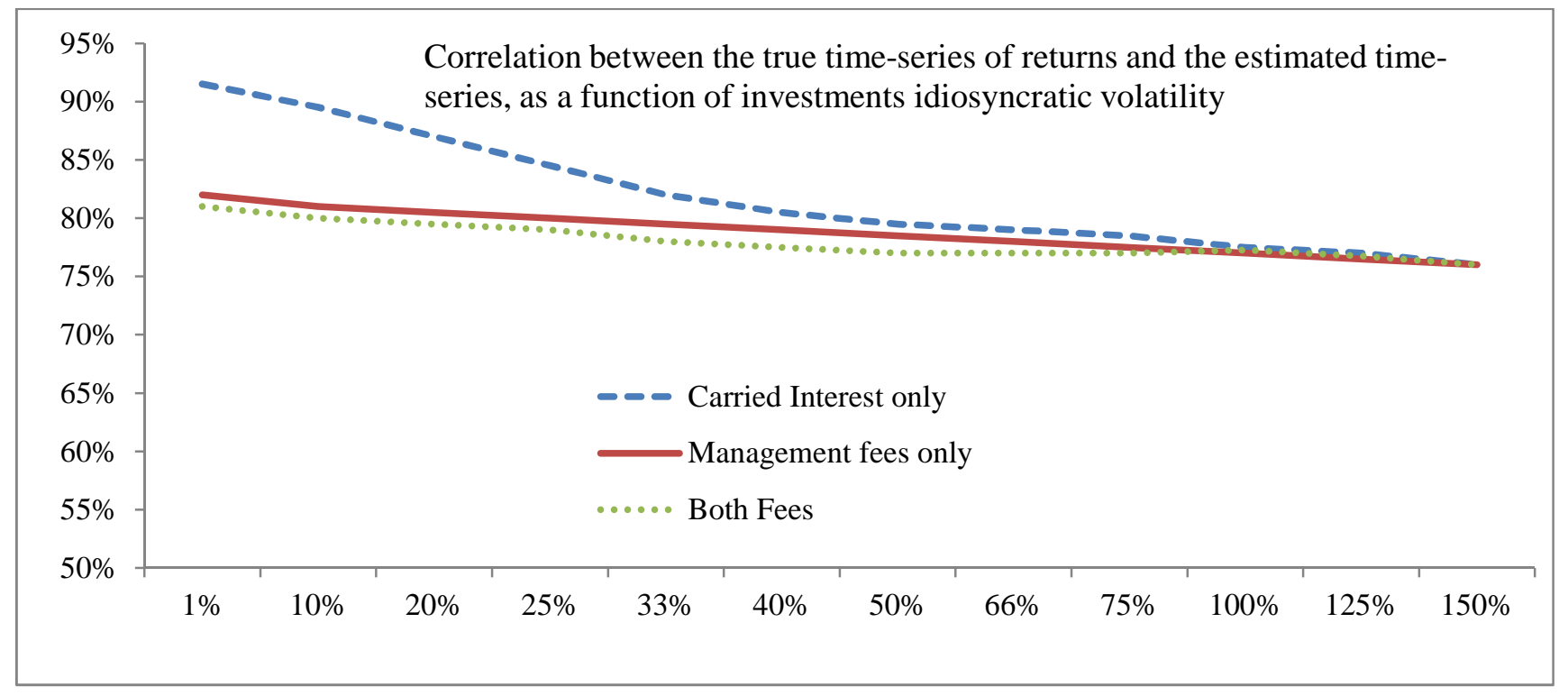

Panel B: Carried interest is modelled as a continuous latent call option

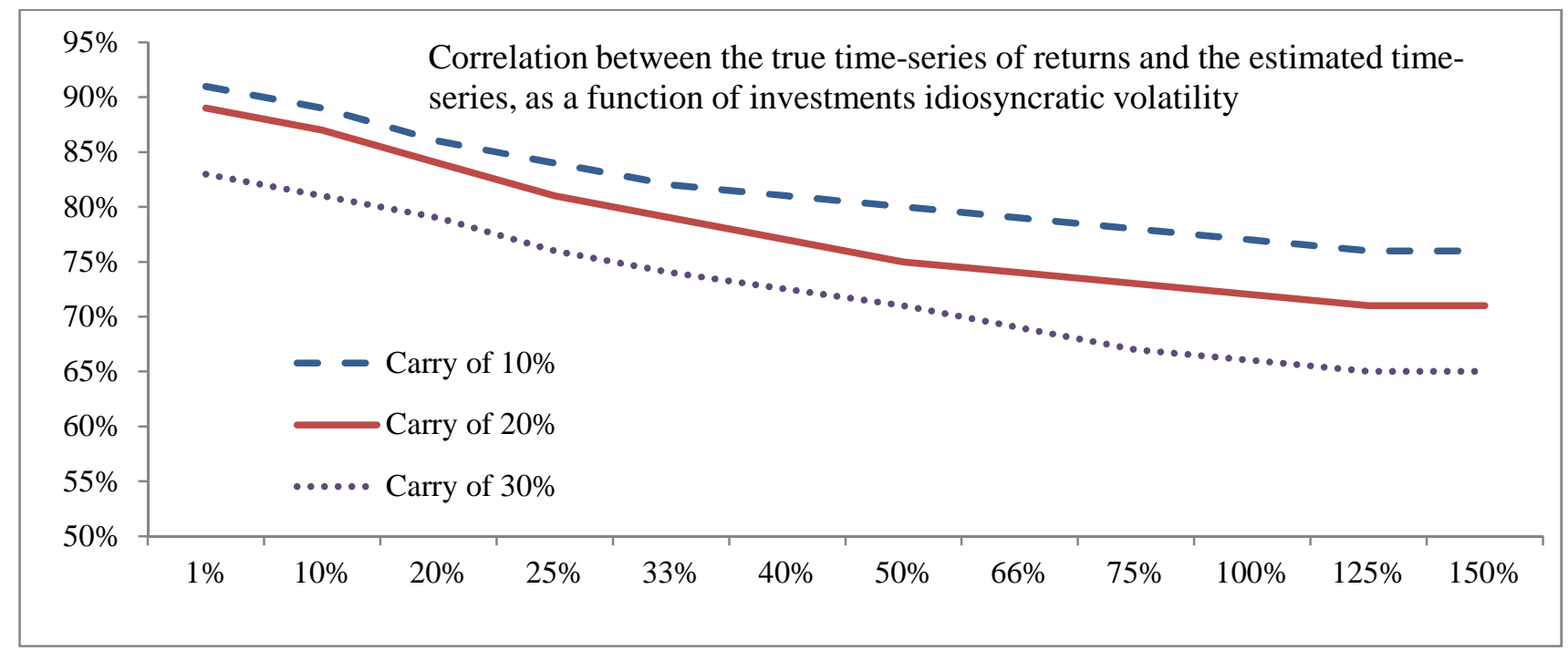


Panel A: Cumulated log returns per sub-type of US private equity funds

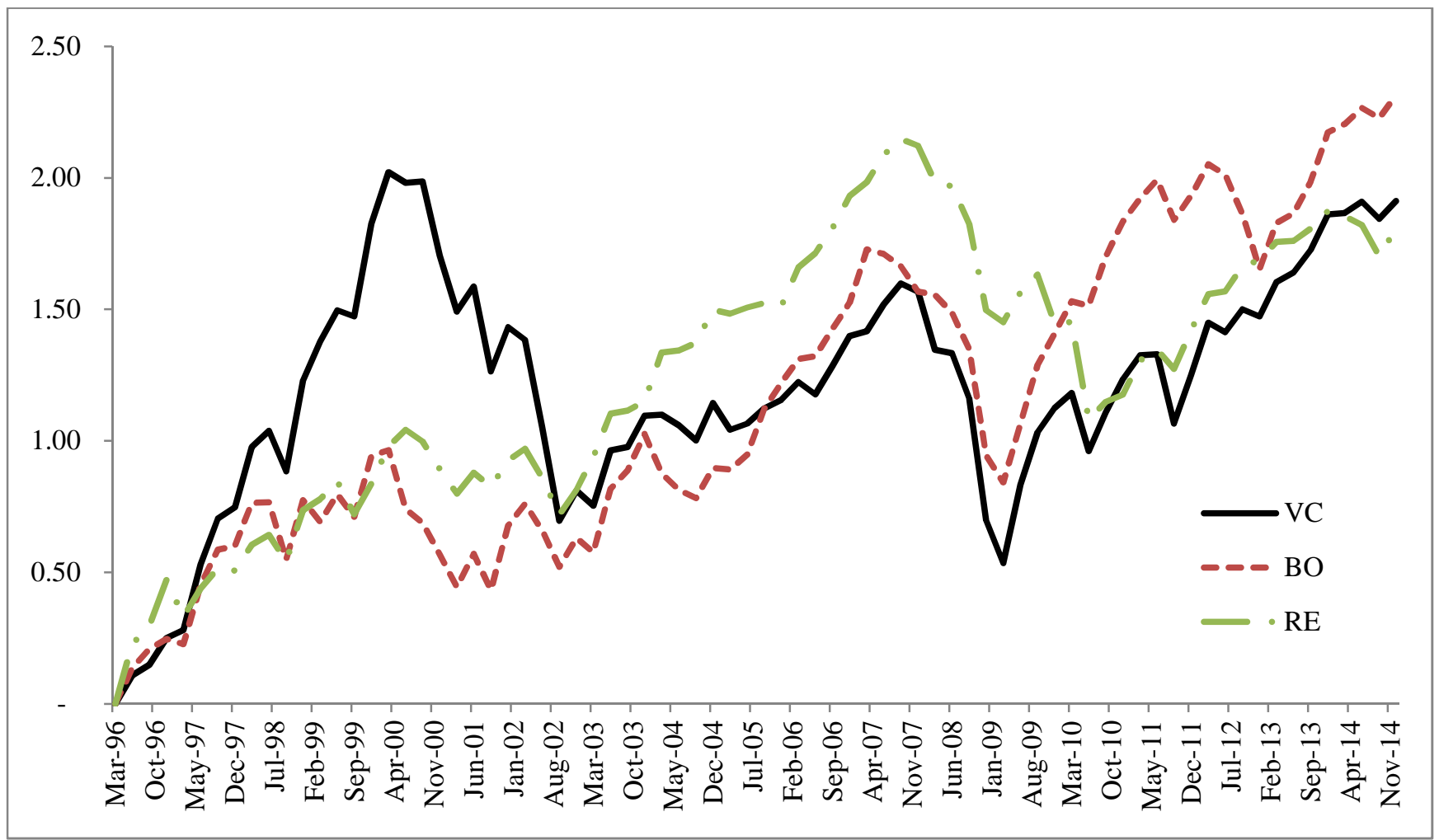

Panel B: Cumulated log returns of US buyout funds, the S\&P 500 index and the DFA value fund

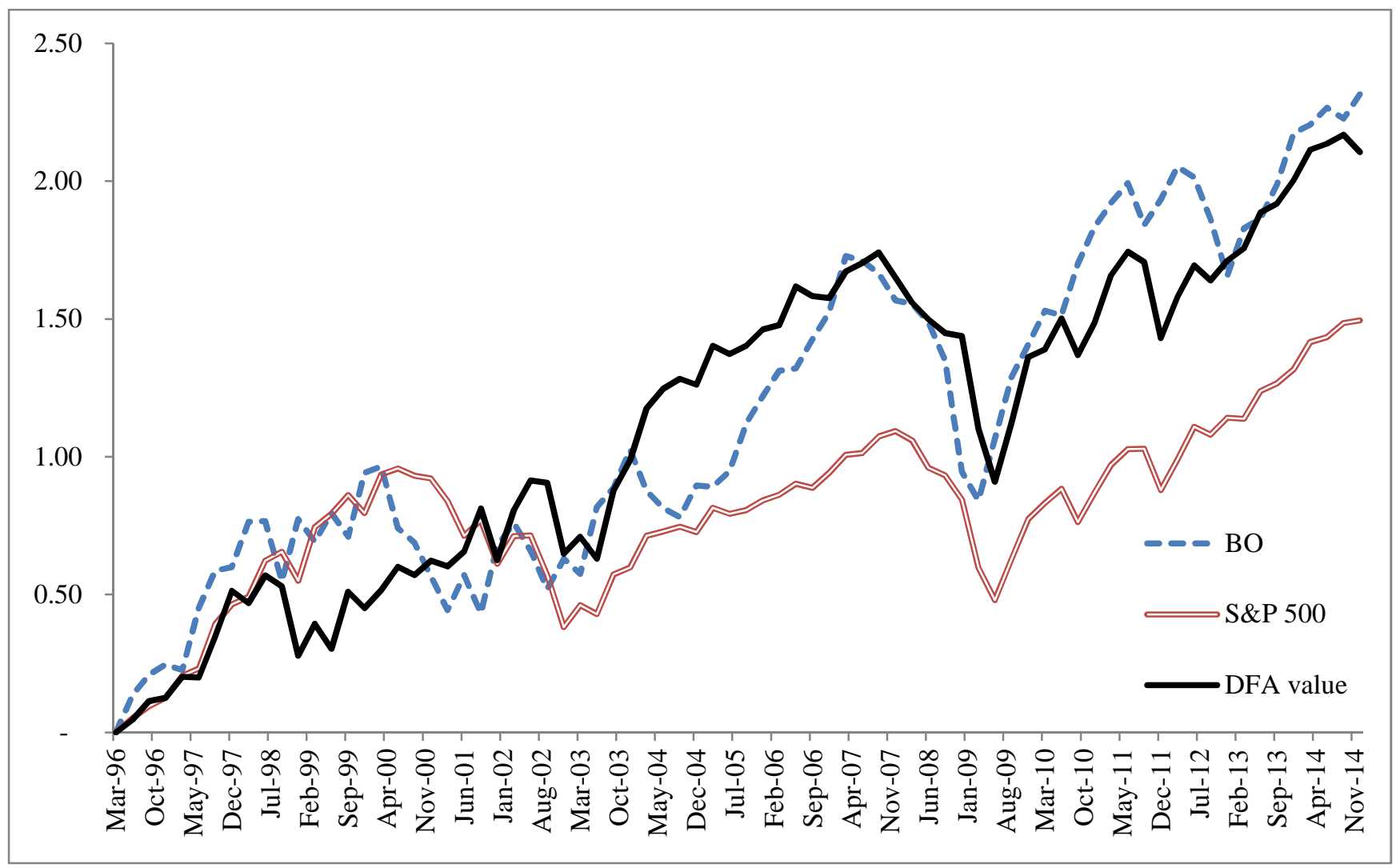

